\title{
MINERALOGIA, MORFOLOGIA E CRISTALOQUÍMICA DA MONAZITA DE CATALÃO I (GO, BRASIL)
}

\author{
MARIA CRISTINA MOTTA DE TOLEDO' ${ }^{1}$, SONIA MARIA BARROS DE OLIVEIRA ${ }^{1}$, \\ FRANÇOIS FONTAN ${ }^{2}$, VIVIANE CARILLO FERRARI ${ }^{1} \&$ PHILIIPPE DE PARSEVAL $^{2}$
}

\begin{abstract}
MINERALOGY, MORPHOLOGY, AND CRYSTAL-CHEMISTRY OF MONAZITE FROM CATALÃO $I(G O, B R A Z I L)$ The Catalão alkaline carbonatite complex hosts a number of mineral resources including monazite. This mineral is a common accessory phase in two lithological units: carbonatite and silexite. Textural evidence suggest that monazite replaced carbonates in the carbonatite and crystallized simultaneously with quartz in the silexite. Monazite was resistant to the strong laterization that affected the massif, except for the incipient transformation into gorceixite or cerianite. In both carbonatite and silexite, monazite occurs as a complex aggregate of sub-micrometric crystals, showing unusual morphological and chemical characteristics. It contains $\mathrm{Ca}, \mathrm{Sr}$, and $\mathrm{Ba}$ in the $\mathrm{A}$-site, and shows a certain degree of hydration indicated by ATD and IV data. Structural formulae calculated on the basis of sum of cations $=1$ show a moderate ionic deficiency in the anionic site. Rietveld reffinement indicated poor crystallinity. Notwithstanding these peculiar characteristics, cell dimensions are similar to those of standard monazite.

Keywords: monazite, rare-earth elements, carbonatite, barium, strontium, Catalão I.

Resumo O complexo alcalino-carbonatítico de Catalão I contém diversos recursos minerais incluindo monazita, que é uma fase acessória comum em duas unidades litológicas: carbonatito e silexito. Evidências texturais sugerem que a monazita substitui os carbonatos no carbonatito e cristaliza simultaneamente ao quartzo no silexito. A monazita mostrou-se resistente à alteração laterítica que afetou o complexo, exceto pela incipiente transformação em gorceixita e em cerianita. Em ambas as rochas a monazita ocorre como complexos agregados de cristais submicrométricos, com morfologias e composição química incomuns. A monazita contém Ca, Sr e Ba no sítio A e mostra um certo grau de hidratação, indicado pelos dados de ATD e EIV. As fórmulas estruturais calculadas na base soma dos cátions=1 mostra moderada deficiência no sítio aniônico. O refinamento da estrutura segundo o método de Rietveld indica pobre cristalinidade. Não obstante estas características peculiares, as dimensões da cela unitária são similares à monazita padrão.
\end{abstract}

Palavras-chave: monazita, Elementos Terras Raras, carbonatito, Catalão I, bário, estrôncio.

INTRODUÇÃo O complexo de Catalão I (GO) O complexo ultramáfico-alcalino-carbonatítico de Catalão I está localizado no sudeste do Estado de Goiás ( $15 \mathrm{~km}$ a nordeste da cidade de Catalão e $280 \mathrm{~km}$ ao sul de Brasília), a $18^{\circ} 08^{\prime}$ de latitude sul e $47^{\circ} 48^{\prime}$ de longitude oeste. A estrutura forma um platô subcircular - eixos NW e NE com cerca de 6 e 5,5 km, respectivamente -, sustentado por rochas quartzíticas encaixantes fenitizadas quando da intrusão do complexo. Está em altitude média de $900 \mathrm{~m}$, elevando-se cerca de $100 \mathrm{~m}$ acima dos terrenos circundantes. A parte interna da elevação apresenta relevo suave e condições favoráveis ao aprofundamento dos perfis de alteração, que chegam a atingir mais de $100 \mathrm{~m}$ de espessura (Carvalho 1974).

O clima atual é tropical úmido, com média anual de temperatura de $22^{\circ} \mathrm{C}$ e média anual de precipitação de $1750 \mathrm{~mm}$, com pluviosidade mais elevada de setembro ou outubro até março ou abril.

Catalão I é um dos vários complexos alcalino-carbonatíticos mesozóicos que ocorrem nas bordas da Bacia do Paraná, ao longo de falhas profundas, com direção NW. A intrusão do complexo, no Cretáceo superior, deformou os quartzitos e micaxistos do Gru- po Araxá (Proterozóico Médio). Flogopititos e carbonatitos são os principais tipos litológicos observados, ocorrendo em complexas associações de alternância (Fig. 1). Dunitos, piroxenitos e foscoritos estão presentes subordinadamente.

Vários autores estudaram o complexo de Catalão, do ponto de vista geológico, mineralógico e econômico. Entre eles destaca-se Vallarelli (1971) que, em estudo sistemático da mineralogia de Catalão I, reconheceu opticamente a presença de rabdofânio, e, por difração de raios- $\mathrm{X}$, de monazita e outros fosfatos.

Ulbrich \& Gomes (1981) apresentaram uma classificação dos complexos alcalinos brasileiros na qual Catalão I está incluída no tipo III, caracterizado pela predominância de flogopititos e carbonatitos. Araújo \& Gaspar (1992) mencionaram ainda a presença de anfibólio-flogopitito e bebedourito. Segundo esses autores, os carbonatitos de Catalão I seriam resultado de intenso autometassomatismo potássico a que teriam sido submetidas as rochas ultramáficas primárias. Os minerais de Catalão I são, de modo geral, semelhantes aos de outros complexos similares do mundo. Contudo, é excepcional a presença, nos flogopititos, de priderita - óxido de $\mathrm{K}, \mathrm{Ba}$, Ti e Fe -, mineral que tem sido descrito

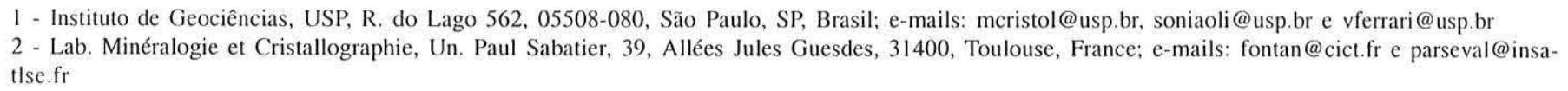




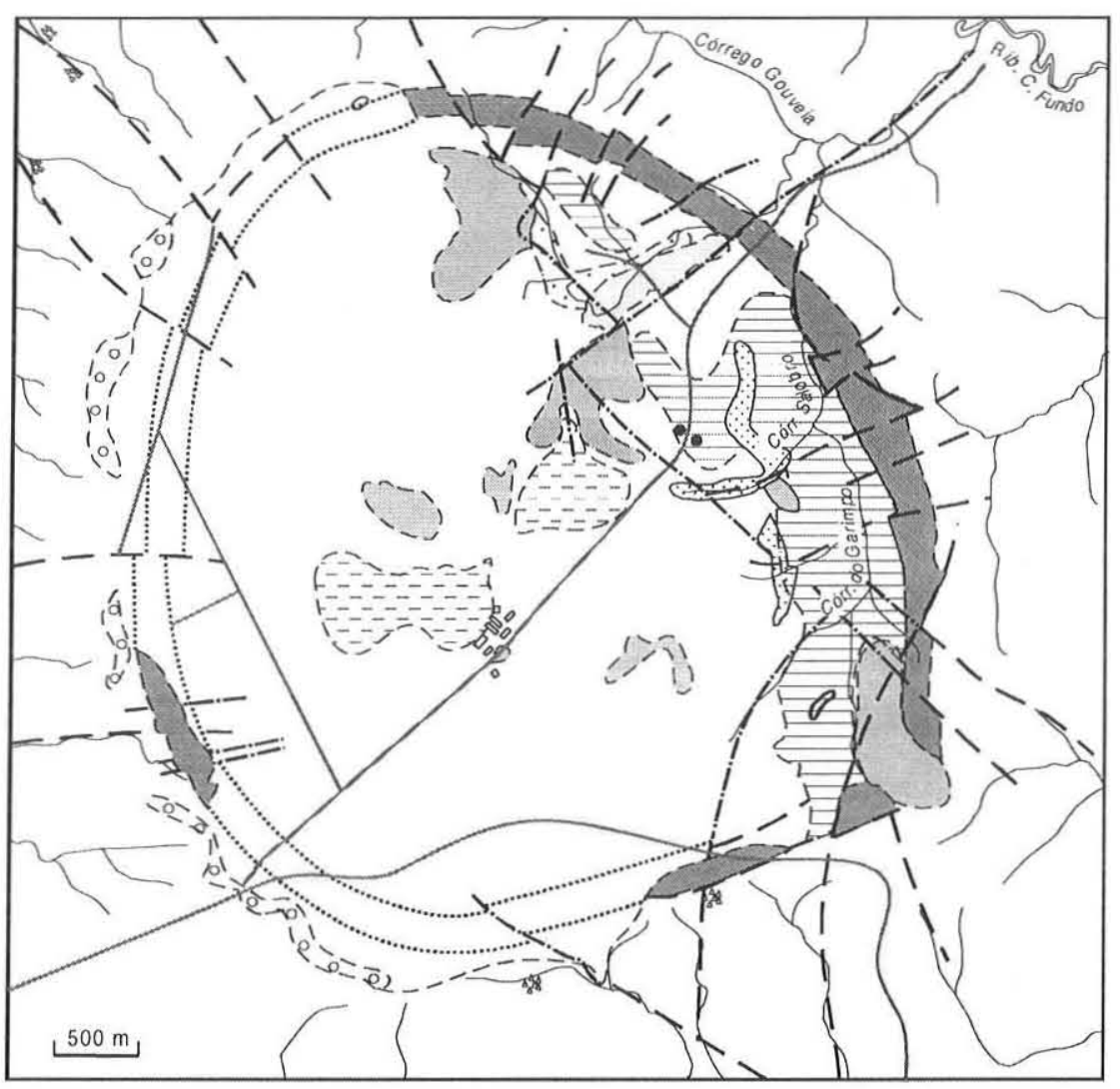

NE

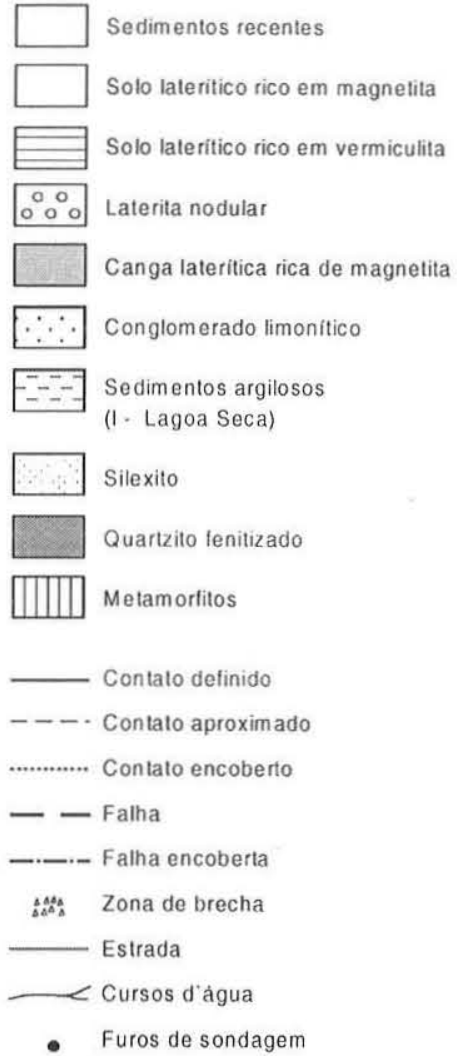

SW

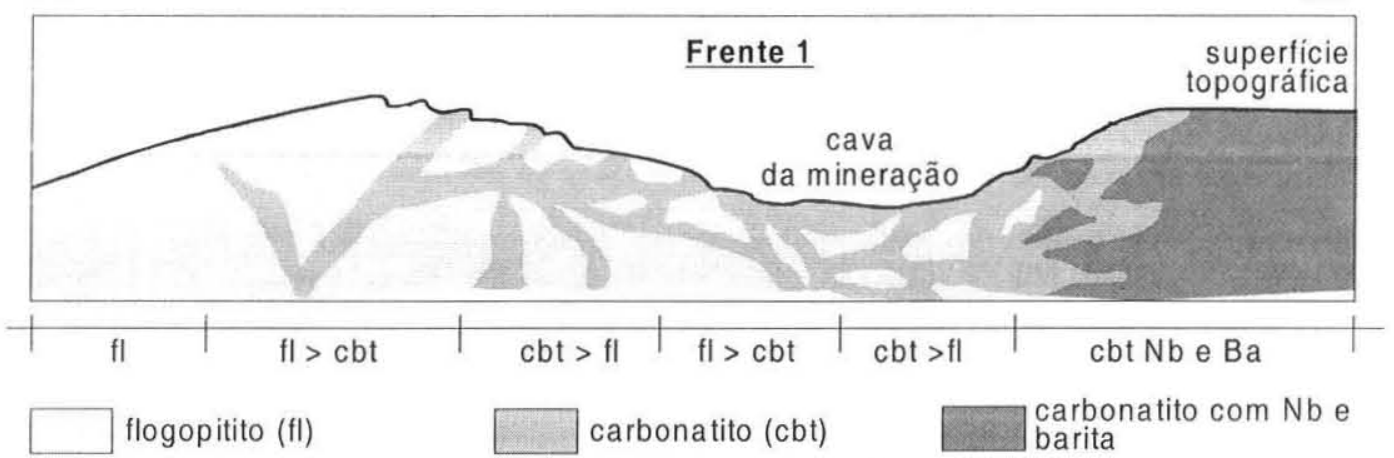

Figura I - Mapa geológico do centro-sul do Brasil, com a localização de alguns dos complexos alcalino-carbonatíticos (Rodrigues \& Lima 1984), mapa das formações superficiais do complexo de Catalão I (Baecker 1983 e Carvalho 1974) e perfil geológico hipotético.

apenas em kimberlitos e lamproítos (Araujo \& Gaspar 1992).

Lapido-Loureiro (1995) considerou que também os flogopititos seriam resultado da transformação, por intenso autometassomatismo potássico, das rochas ultramáficas primárias (dunitos e piroxenitos), formando flogopita, carbonato, opacos (magnetita, ilmenita e pirita), apatita, serpentina, clinohumita e titanita. Identificou quatro processos de transformação das rochas do complexo - flogopitização, carbonatização, serpentinização e silicificação -, que já haviam sido mencionados por Carvalho (1974). LapidoLoureiro (1995) destacou as grandes dimensões e o caráter irregular dos volumes de carbonatito silicificado em Catalão I. Explicou a silicificação desses grandes volumes de rocha com base tanto nas reações das rochas ultrabásicas intrusivas com o $\mathrm{CO}_{2}$ juvenil, for- mando flogopita e carbonato e liberando sílica, como a partir da fenitização das rochas silicáticas encaixantes, provocada pela intrusão do carbonatito, processo que promoveria uma dessilicificação das rochas, liberando sílica para a formação dos silexitos.

Baecker (1983) identificou três eventos magmáticos na gênese do complexo. No primeiro as rochas geradas foram foscoritos e piroxenitos, no segundo, carbonatito sovítico, e no terceiro, carbonatito magnesiano. Entre o segundo e o terceiro evento há fortes evidências de hidrotermalismo com geração de veios de apatita, quartzo e barita. Outro evento hidrotermal mais tardio foi responsável pela generalizada silicificação que afetou as rochas do complexo. Pereira (1995) também reconheceu as gerações 
magmáticas e hidrotermais entre as rochas presentes, tendo ainda estudado seu intemperismo.

$\mathrm{O}$ intemperismo desenvolveu sobre as rochas do complexo um espesso manto que pode ultrapassar $100 \mathrm{~m}$, onde houve concentração de fosfato, nióbio, elementos terras raras, titânio e vermiculita. As concentrações de apatita foram formadas essencialmente por acumulação residual durante a alteração, embora haja alguma neoformação de apatita supérgena (Toledo 1999). A evolução laterítica do carbonatito e o comportamento dos ETR durante esse processo foram estudados por Oliveira \& Imbernon (1998). Tassinari et al. (1998) estudaram aspectos referentes à caracterização tecnológica dos materiais ricos em ETR, indicando tratar-se de material de difícil separação em vista da granulação extremamente fina. O mesmo fez Neumann (1999), com as concentrações monazíticas associadas aos silexitos (média de $10,05 \% \mathrm{TR}_{2} \mathrm{O}_{3}$ ), aos materias lateríticos (média de $8,39 \% \mathrm{TR}_{2} \mathrm{O}_{3}$ ), e ao carbonatito fresco (média de 6,64\% $\mathrm{TR}_{2} \mathrm{O}_{3}$ ), concluindo que todos os tipos são, por enquanto, inviáveis para aproveitamento econômico, devido à sua forma de ocorrência. $\mathrm{O}$ fato de a monazita ocorrer finamente cristalizada e em íntima associação com os minerais de ganga impossibilita liberação suficiente, a não ser por meios demasiadamente onerosos.

Das cinco riquezas minerais principais no complexo - apatita, pirocloro, monazita, anatásio e vermiculita - apenas as duas primeiras estão em processo de lavra. O fosfato é minerado pela Ultrafértil e pela Copebrás, e o nióbio, pela Mineração Catalão. Com relação aos depósitos de ETR, foram identificados dois tipos, um de suposta origem hidrotermal, associado ao silexito na área do Córrego do Garimpo, e um residual, associado ao manto de alteração derivado do carbonatito/flogopitito, onde também se concentram apatita, anatásio e pirocloro.

Apesar de o complexo de Catalão I estar sendo estudado sistematicamente há mais de 30 anos, apenas muito recentemente seus fosfatos vêm sendo conhecidos com maior detalhe (Toledo 1999, Neumann 1999, Toledo et al. 2002). Até o momento ainda não foi realizada uma caracterização pormenorizada de um de seus principais minerais de minério - a monazita. O presente trabalho, que traz dados mineralógicos e cristaloquímicos referentes à monazita associada ao silexito e ao carbonatito, visa preencher essa lacuna.

Monazita O grupo estrutural da monazita é constituído, segundo Fleischer et al. (1990), por arsenatos, fosfatos e silicatos monoclínicos de fórmula geral $\mathbf{A} \mathbf{B} \mathbf{O}_{4},(\mathbf{A}=\mathrm{Bi}, \mathrm{Ca}, \mathrm{Ce}, \mathrm{La}, \mathrm{Nd}, \mathrm{Th}$, $\mathrm{U}$ e $\mathbf{B}=\mathrm{As}, \mathrm{P}, \mathrm{Si})$. Dentro desse grupo, o fosfato monazita é o mais comum mineral de ETR, ocorrendo em vários ambientes geológicos, com ampla diversidade de composição e morfologia.

Na estrutura da monazita, os cátions trivalentes de ETR estão coordenados por nove átomos de oxigênio. Os poliedros assim delimitados compartilham vértices, formando cadeias ao longo da direção $b$; essas cadeias estão ligadas na direção $c$ por tetraedros $\left(\mathrm{PO}_{4}{ }^{3-}\right)$ que compartilham vértices com os poliedros das cadeias adjacentes, formando uma camada paralela ao plano (100). Essas camadas estão empilhadas na direção $a$, compartilhando os vértices entre os poliedros $\mathrm{ETRO}_{9}$ para formar cadeias em ziguezague na direção [101] (Huminicki \& Hawthorne 2002). A estrutura da monazita incorpora preferencialmente os ETR leves, maiores, em comparação ao xenotimo, em cuja estrutura estão alojados os ETR mais pesados e menores (Ni et al. 1995).

A síntese mais ampla sobre a ocorrência deste mineral é encontrada em Overstreet (1967). A monazita ocorre em variados ambientes geológicos (magmáticos, metamórficos, hidrotermais e intempéricos), com ampla distribuição como mineral acessório em rochas metamórficas de grau alto e intermediário, derivadas de sedimentos argilosos, como xistos, gnaisses e migmatitos. Raramente está presente em calcários e calcários metamórficos. Em rochas magmáticas, ocorre em diorito e granito a muscovita, além de pegmatitos e veios de quartzo. Entre as rochas alcalinas, é encontrada em nefelina-sienitos e sienitos pegmatíticos, sendo abundante em carbonatitos, e ainda em rochas alcalinas vulcânicas e diques relacionados. Devido à sua alta estabilidade química e física, concentra-se em depósitos tipo placer, sendo os placers marinhos o ambiente dos depósitos economicamente mais importantes. No entanto, há referências na literatura sobre a alteração de monazita por intemperismo (Mariano 1989; Neuman 1999), assim como sobre sua geração pelo mesmo processo (Rose et al. 1958, Mitchell et al. 1976, Rosemblum \& Mosier 1983, Preinfalk \& Morteani 1986, Lottermoser 1990, Chakhmouradian \& Mitchell 1998).

Junto com a bastnaesita, a monazita é mineral de minério dos principais depósitos de ETR no mundo. Suas características morfológicas e químicas influem na qualidade dos minérios e na eficácia dos processos industriais de concentração (Lapido-Loureiro 1994, Neuman 2000). Desde a década de 70, a importância da monazita alcançou o âmbito da ciência ambiental, pois sua estrutura estável tem sido investigada por representar um modelo para um composto sintético ideal passível de imobilizar radionuclídeos presentes em lixo radiativo (McCarthy et al. 1978, Ewing \& Wang 2002). Não obstante, alguns trabalhos recentes têm indicado a necessidade de revisão do suposto caráter inerte da monazita (Hecht \& Cuney 2000, Poitrasson et al. 2000, Read et al. 2002).

No Brasil, os depósitos mais importantes de monazita para aproveitamento econômico são os placers marinhos situados no estado de Espírito Santo (Leonardos Jr. 1974). A monazita ocorre também associada a carbonatitos e seus produtos de alteração laterítica, mas até hoje esses depósitos não apresentaram viabilidade econômica.

\section{AMOSTRAGEMETÉCNICASANALÍTICAS Amonazitaem}

Catalão I ocorre em duas situações distintas: como mineral do carbonatito fresco ou intemperizado (associada a carbonatos, apatita e, menos comumente, quartzo, além de minerais gerados pelo intemperismo como goethita, crandallita e argilominerais), e como mineral do silexito (associada ao quartzo, barita e apatita e aos minerais supérgenos, goethita e hollandita).

Para este estudo, foram utilizadas amostras das duas situações mencionadas, retiradas de furos de sondagem, no caso da associação com os carbonatitos, e de afloramentos expostos pelos trabalhos de mineração de fosfato no complexo, na área do Córrego do Garimpo, no caso da associação com os silexitos. Os critérios utilizados na amostragem em cada caso foram distintos. A amostragem do carbonatito visou investigar o efeito do intemperismo sobre a monazita. Em função disso, procurou-se amostrar monazita associada a rochas com graus de intemperismo variável, isto é, desde carbonatito bastante intemperizado, encontrado a profundidades reduzidas, a carbonatito que mostrasse grau de alteração apenas incipiente, o que ocorre com as amostras de maiores profundidades. No caso da amostragem do silexito, as amostras expostas na frentes de lavra não apresentavam diferenciação visível em termos de grau de alteração intempérica. Assim, na amostragem considerou-se apenas a variação mesoscópica das concentrações de monazita, em geral expressas por sutis diferenças de coloração. A localização das sondagens e do Córrego 
do Garimpo podem ser vistas na figura 1.

O material foi estudado por várias técnicas analíticas para definição das características de interesse: Difração de Raios-X (DRX), Análise Térmica Diferencial e Gravimétrica (ATD-TG), Espectroscopia de Absorção no Infra Vermelho(IV), Microscopia Óptica (MO), Microssonda Eletrônica (ME) e Microscopia Eletrônica de Varredura com sistema de análise por dispersão de energia (MEV-EDS), tendo sido estudadas imagens tanto de elétrons secundários (SEI) como de elétrons primários (BEI).

Os difratogramas de raios- $\mathrm{X}$ foram adquiridos a partir de um difratômetro Siemens D500 de geometria Bragg-Brentano. Foram empregadas as seguintes condições: radiação $\mathrm{CuKa}(l=1,5418 \AA$ ) produzida a $40 \mathrm{KV}$ e $40 \mathrm{~mA}$, espelho ajustado para feixe de $0,2 \mathrm{~mm}$, campo do goniômetro $15-50^{\circ} 2 \mathrm{q}$, tamanho do passo $=0,01^{\circ} \mathrm{e}$ tempo de contagem de $5 \mathrm{~s} /$ passo.

As análises por MEV-EDS, para micromorfologia e identificação química qualitativa, foram realizadas no Laboratório de Microscopia Eletrônica do NUPEGEL, USP, em equipamentos JEOL, modelos JSM-T330A, acoplado a sistema EDS Noran.

As análises químicas quantitativas microlocalizadas foram feitas no "Service d'analyse par microsonde electronique" da Universidade Paul Sabatier (Toulouse, França) em equipamento CAMECA SX-50 (EMPA), equipada com três espectrômetros de dispersão de comprimento de onda (WDS), com tensão de aceleração de $15 \mathrm{kV}$ e corrente de $20 \mathrm{nA}$. Os padrões utilizados foram wollastonita para $\mathrm{Ca}$ e $\mathrm{Si}, \mathrm{MnTiO}_{3}$ para $\mathrm{Mn}$, hematita para $\mathrm{Fe}$, $\mathrm{Al}_{2} \mathrm{O}_{3}$ para $\mathrm{Al}, \mathrm{BaTiO}_{3}$ para $\mathrm{Ba}$ e $\mathrm{SrTiO}_{3}$ para Sr. Além destes, foram usados os seguintes padrões sintéticos de ortofosfatos, preparados por J.M. Montel no Laboratoire de Minéralogie et Crystallographie da Universidade Paul Sabatier (França): $\mathrm{LaPO}_{4}$ para $\mathrm{PeLa}, \mathrm{CePO}_{4}$ para Ce, $\mathrm{Pr} \mathrm{PO}_{4}$ para $\mathrm{Pr}, \mathrm{Sm} \mathrm{PO}_{4}$ para Sm, GdPO4 para Gd e Dy PO4 para Dy. Em adição, o composto sintético $\mathrm{YPO}_{4}$ proveniente do Smithsonian Institute foi utilizado para $\mathrm{Y}^{4}$ (Jarosewich \& Boatner 1991). O tempo de contagem foi de 10 segundos para os picos e de 5 segundos para o fundo. As linhas $\alpha$ foram utilizadas para os ETR, exceto $\mathrm{Ce}$, para o qual foi utilizada a raia $\beta$ e evitar a interferência com a raia $\alpha$ do $B$ a. Os limites de detecção, em porcentagens em peso dos elementos dosados, foram de 0,22 para $\mathrm{La}, 0,86$ para $\mathrm{Ce}, 0,72$ para $\mathrm{Pr}, 0,62$ para Nd, 0,57 para $\mathrm{Sm}, 0,70$ para $\mathrm{Gd}, 0,38$ para $\mathrm{Dy}, 0,16$ para $\mathrm{Y}, 0,04$ para $\mathrm{Ca}, 0,24$ para $\mathrm{Sr}, 0,43$ para $\mathrm{Ba}, 0,16$ para $\mathrm{Mn}, 0,12$ para $\mathrm{Fe}, 0,28$ para $\mathrm{U}, 0,05$ para $\mathrm{Al}, 0,07$ para $\mathrm{P}, 0,05$ para Si e 0,30 para $\mathrm{Th}$.

O equipamento de análise simultânea ATD-TG utilizado é da marca TA instruments, modelo SDT 2960, do Instituto de Geociências da USP, tendo as análises sido feitas com velocidade de aquecimento de $5^{\circ} \mathrm{C} / \mathrm{min}$ e registro a partir da temperatura ambiente até $1000^{\circ} \mathrm{C}$.

O espectrômetro de absorção na região do infravermelho utilizado foi um modelo MB 102 marca Bomen, do Instituto de Química da USP; foram utilizadas pastilhas com $\mathrm{KBr}$, tendo sido analisado o intervalo de 400 a $4000 \mathrm{~cm}^{-1}$, com resolução de $4 \mathrm{~cm}^{-1}$.

\section{RESULTADOS E DISCUSSÃO Descrição mineralógica e} morfológica No carbonatito, a monazita apresenta-se, macroscopicamente, como volumes diferenciados mais ou menos descontínuos, de dimensão milimétrica, formados por material finamente granulado, geralmente esverdeado, friável ou não. Nas partes mais profundas dos furos a monazita está associada com carbonatos (principalmente dolomita, mas também magnesita) e apatita; em níveis mais superficiais, onde os carbonatos já sofreram dissolução, a associação é sobretudo com apatita e minerais secundários como goethita, crandallita e argilominerais.

Em escala microscópica, também observa-se a impregnação e substituição de partes da rocha pela monazita (Fig. 2a), formando volumes irregulares, muito porosos, relativamente difusos ou com limites bem definidos, assumindo formas sub-romboédricas, ora angulosas (Fig. 2b), ora arredondadas (Fig. 2c, 2d e 2f). Constituem material finamente cristalizado, de modo que as características morfológicas e ópticas dos cristais não são observáveis. São geralmente turvos, incolores ou amarelo-esverdeados. Esses volumes podem eventualmente apresentar-se como agregados coalescidos muito porosos (Fig. 2c), de estrutura interna concêntrica (Figs. 2c e 2f) ou esponjosa, às vezes de aspecto fibroso (Fig. 2e). As camadas concêntricas têm geralmente espessura menor que $1 \mu \mathrm{m}$ e são separadas por espaços vazios ou por monazita altamente porosa. Morfologia semelhante foi encontrada por Bulakh et al. (2000) em monazita dos complexos carbonatíticos de Kandaguba e de Vuoriyarvi (Kola, Rússia). A forma de ocorrência em Catalão I indica que a monazita representa uma fase posterior à etapa magmática primária, com características texturais de material invasivo, impregnando e substituindo irregularmente minerais préexistentes, principalmente os carbonatos (Fig. 2a), mas também o quartzo (Fig. $2 \mathrm{~g}$ ) e a apatita.

Não há uma relação evidente entre a morfologia da monazita e o grau de alteração do carbonatito. Porém, com alteração crescente, os volumes de monazita apresentam-se associados cada vez mais intimamente com as fases secundárias. Nas amostras de carbonatito em estágio inicial de alteração, observa-se que os carbonatos impregnados por monazita parecem resistir melhor à dissolução (Fig. $2 h$ ). Na rocha mais alterada, onde a fase carbonática já foi totalmente dissolvida, o processo de ferruginização em vias de instalação atinge também as concentrações monazíticas (Fig. 2i), terminando por englobar completamente os volumes de monazita. No entanto, os agregados de monazita parecem intocados pela alteração intempérica, a não ser em raros casos nos quais há sinais de incipiente transformação que pode ser atribuída ao intemperismo, formando volumes micrométricos dentro ou nas bordas dos agregados de monazita, diferenciáveis apenas pela composição química observada ao MEV/EDS ou à ME. Estas composições são indicativas de gorceixita, estudada por Toledo et al.(2002), ou de uma fase a ETR sem P (provavelmente cerianita, detectada somente em análises por MEV-EDS e ME). Mariano (1989) interpretou a origem da cerianita associada à monazita supérgena em Araxá (MG, Brasil), como resultante da precipitação de $\mathrm{Ce}^{4+}$ proveniente da perda de $\mathrm{Ce}^{3+}$ da monazita supérgena em relação a monazita de origem endógena. A ocorrência de cerianita como produto de alteração da monazita em Catalão I já foi mencionada por Morteani \& Preinfalk (1996) e por Neumann (1999). A formação de cerianita deve ter ocorrido a partir da liberação de $\mathrm{Ce}^{3+}$ da monazita, oxidação em $\mathrm{Ce}^{4+}$, e precipitação do óxido.

A monazita associada às rochas silicificadas da área do Córrego do Garimpo também não forma cristais bem desenvolvidos. Ocorre em concentrações criptocristalinas mais ou menos bem individualizadas ou intimamente misturadas ao quartzo, com aspecto macroscópico fibroso, formando leques centimétricos, de cor verde amarelada ou, menos comumente, cinza-azulada. Essas formas em leques descontínuos já foram mencionadas por Wall \& Mariano (1996) para monazita de carbonatitos de Kangangunde (Malawi) e de Adiounedj (Mali). Estes autores acreditam que tal morfologia seja resultado da substituição de apatita ou de outros minerais (barbankita e carbocernaíta). Alguns dos volumes monazíticos aqui estudados, observados ao MEV-EDS, também apresentaram 

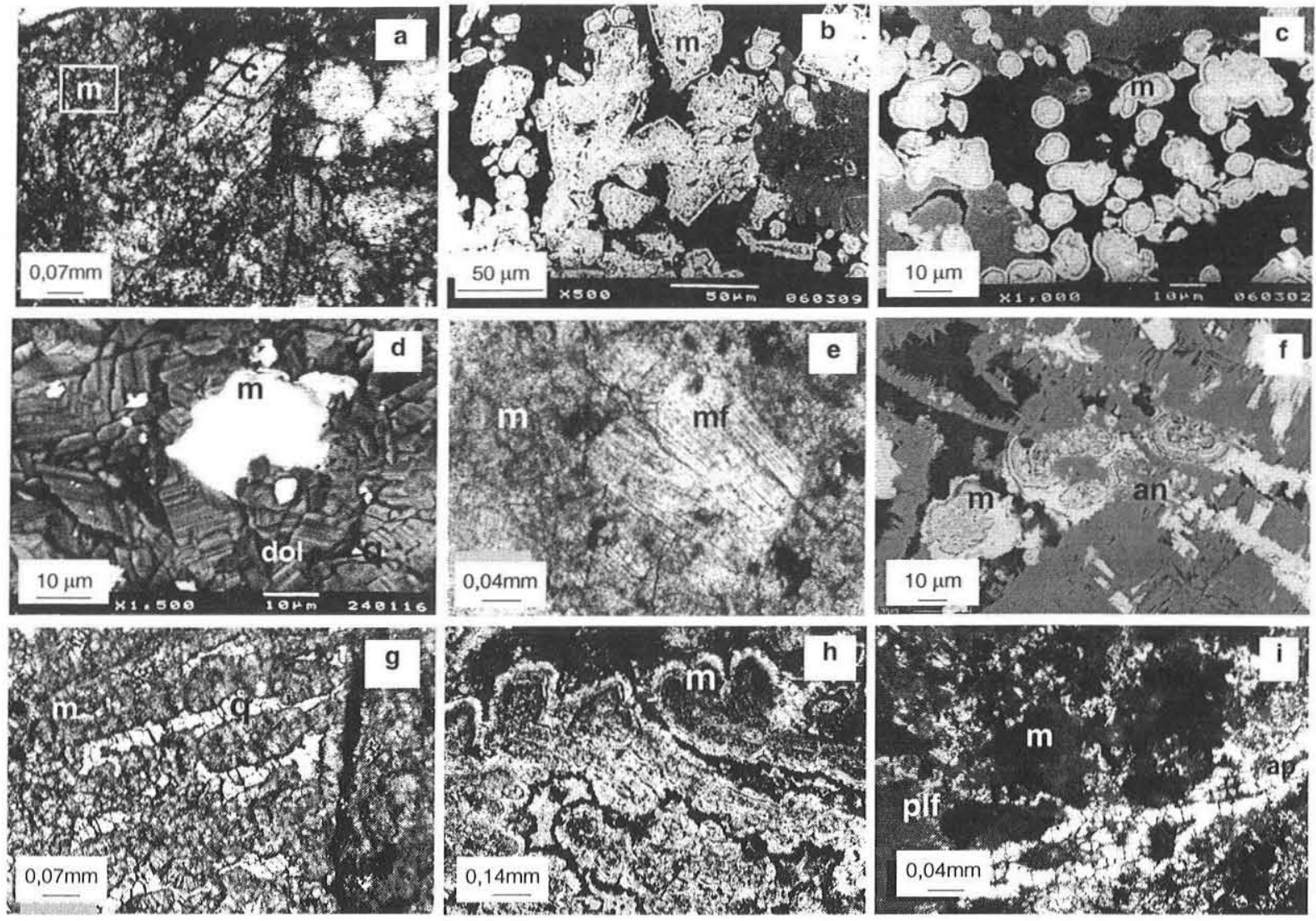

Figura 2 - Aspectos microscópicos da monazita associada ao carbonatito de Catalão I (GO).
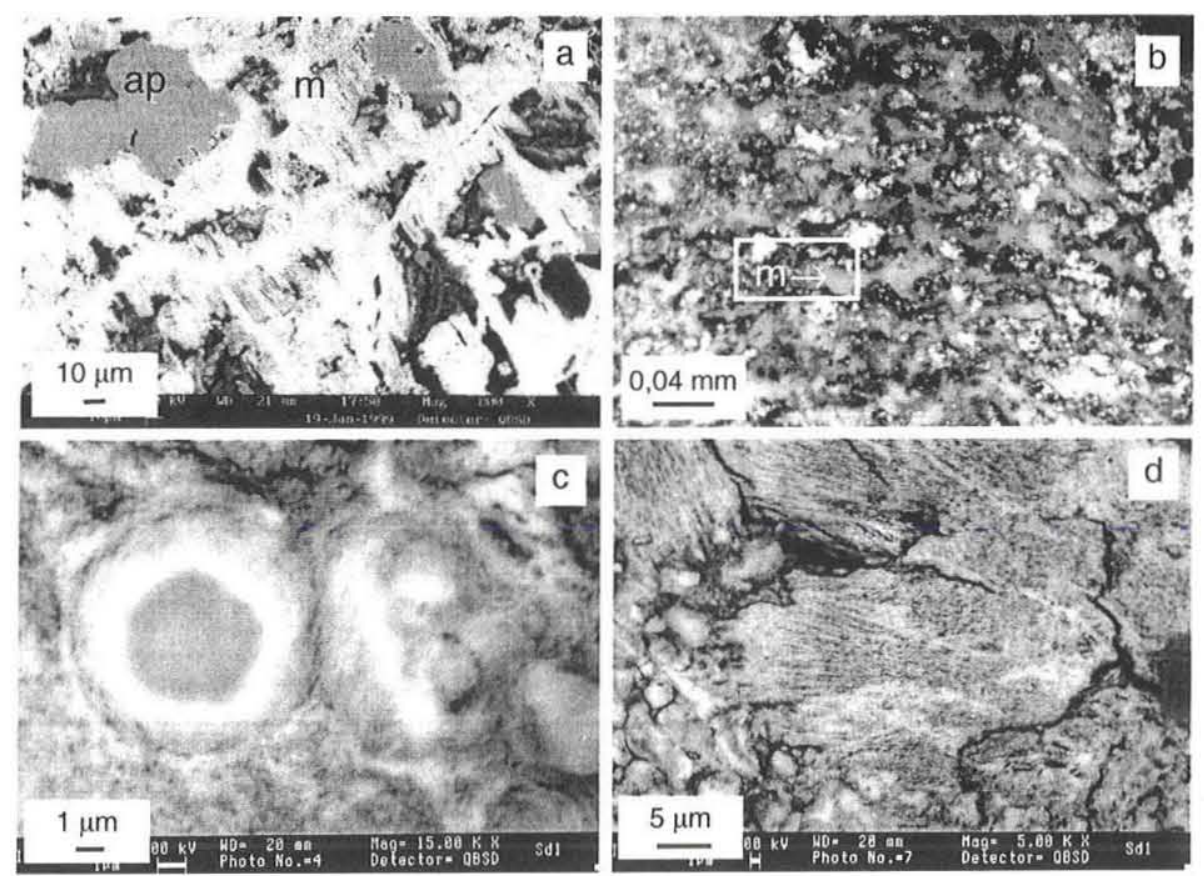

Figura 3 - Aspectos microscópicos da monazita associada ao silexito de Catalão I (GO): a - Monazita (m) substituindo parcialmente apatita (ap), (MEV/BEI), (silexito sill), $b$ - Monazita $(m)$ em volumes irregulares, anastomosados, e quartzo, intimamente associados (MO/LP), (silexito sill), c - Monazita globular (MEV/BEI), (silexito sill) e d-Monazita fibrosa (MEV/BEI), (silexito sill). 
restos de apatita, demonstrando nitidamente o processo de substituição de apatita por monazita (Fig. 3a).

Ao MO, a monazita aparece como concentrações isoladas ou anastomosadas, de contornos muito irregulares e limites não nítidos (Fig. 3b). São agregados lamelares, globulares concêntricos em camadas finíssimas (Fig. 3c) ou fibrosos (Fig. 3d), de aspecto turvo, com heterogeneidades internas quanto à cor e à porosidade. Geralmente é fase posterior à silicificação, embora em alguns casos as relações espaciais indiquem um episódio de silicificação posterior à cristalização da monazita. Nas porções mais alteradas do silexito, a monazita encontra-se impregnada por compostos ferruginosos, provavelmente goethita. Além do quartzo e goethita, apatita e hollandita encontram-se associadas à monazita do silexito.

Características térmicas e espectroscópicas A monazita normalmente não apresenta reações com o aquecimento, sendo suas curvas de ATD sem picos. Molloy (1959) e Deer et al. (1971) atribuem reações exotérmicas eventualmente registradas à presença de produtos ferruginosos. Wall \& Mariano (1996) consideram que, havendo relações genéticas entre a monazita e compostos hidratados, como rabdofânio e outros fosfatos, possíveis misturas podem causar reações de desidratação ou mesmo de recristalização durante as análises térmicas.

Para a amostra de monazita associada ao carbonatito (Mon1), as análises ATD-TG mostram uma leve reação exotérmica causada pela presença do carbonato (magnesita, neste caso), próxima a $700^{\circ} \mathrm{C}$. Além disso, tanto para a monazita do carbonatito como para a do silexito, as análises de ATD-TG mostraram um moderado efeito endotérmico entre $100 \mathrm{e} 300^{\circ} \mathrm{C}$, com perda de massa de cerca $4 \%$ no caso do silexito (Fig. 4). Considerando a ausência de outros minerais passíveis de apresentarem reações térmicas, verificada por DRX, os resultados indicam que as perdas de massa obtidas devem estar relacionadas ou à água adsorvida, ou a ânions $\mathrm{OH}^{-}$ ou $\mathrm{CO}_{3}{ }^{2-}$ presentes na estrutura da monazita. Não se pode, entretanto, descartar a possibilidade de que essa perda de massa seja devida a fases tão pouco abundantes que não foram detectadas à DRX (carbonatos, fosfatos secundários, oxihidróxidos).

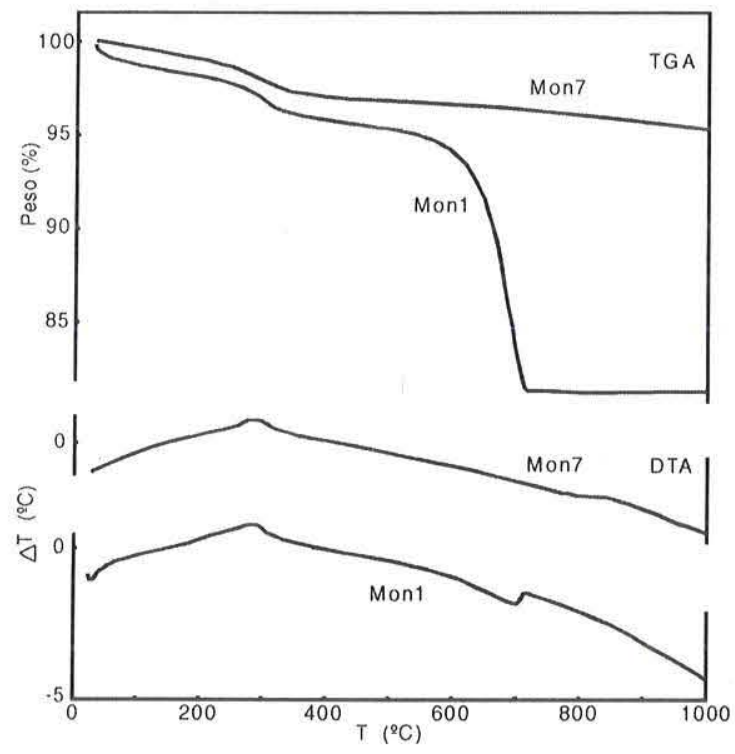

Figura 4 - Termogramas das amostras de monazita associada ao carbonatito e ao silexito.
Vários autores já relataram a possibilidade de ocorrência de $\mathrm{OH}$ ou $\mathrm{H}_{2} \mathrm{O}$ na monazita. Bulakh et al. (2000), em estudo sobre monazita de complexos carbonatíticos de Kola (Rússia), indicaram a presença de $\mathrm{H}_{2} \mathrm{O}$ adsorvida, detectada por espectroscopia no infravermelho, e mencionaram outros autores que também consideraram a existência de "monazita hidratada", como Lottermoser (1990) e Kukharenko et al. (1961, apud Lottermoser 1990). Este caráter hidratado, juntamente com a alta porosidade, foram evocados para justificar os totais baixos em análises à microssonda eletrônica em suas amostras. Segundo Mariano (1989) e Lottermoser (1988 e 1990), em Mt. Weld (Austrália), uma fase fosfática hidratada de ETR (ETR $\mathrm{PO}_{4} \cdot \mathrm{nH}_{2} \mathrm{O}$, hexagonal) pode ter sido precursora da cristalização de monazita, e sua desidratação pode ter causado a conversão para a monazita monoclínica de hábito hexagonal pseudomórfico observada. Vestígios dessa possível fase precursora hidratada podem permanecer em certas amostras de monazita, explicando a existência de $\mathrm{OH}^{-}\left(\right.$ou de $\mathrm{H}_{2} \mathrm{O}$ ) no mineral (Wall \& Mariano 1996). Kucha (1980), estudando a série monazita-huttonita, considerou a possibilidade de haver pequenas quantidades de $\mathrm{OH}^{-}$neste mineral; esta consideração está ligada à sua conclusão de que a série $\mathrm{ETR}_{\mathrm{PO}_{4}}-\mathrm{Th} \mathrm{SiO}_{4}$ somente seria contínua havendo a contribuição de $\mathrm{F}^{4}, \mathrm{OH}^{-}$e $\mathrm{M}^{4+}$ para a manutenção do equilíbrio de cargas na estrutura.

Com a finalidade de esclarecer melhor essas questões, foram realizadas análises por espectrometria de absorção no infravermelho (Fig. 5) para as amostras Mon2 (monazita do carbonatito) e Mon7 (monazita do silexito). As bandas encontradas podem ser correlacionadas a vibrações dos ânions $\mathrm{PO}_{4}^{3-}, \mathrm{CO}_{3}{ }^{2-} \mathrm{e} \mathrm{OH}$, além de $\mathrm{H}_{2} \mathrm{O}$ (Farmer 1974 e Hezel \& Ross 1966).

$\mathrm{A}$ banda intensa e larga na região $1100 \mathrm{~cm}^{-1}$ corresponde às vibrações assimétricas de valência $\mathbf{} \mathbf{3}$ do grupo $\mathrm{PO}_{4}{ }^{3 .}$. Segundo Hezel \& Ross (1966), que estudaram as vibrações de compostos fosfáticos de ETR de mesma estrutura da monazita, nessa região do espectro foram diferenciadas, para os fosfatos anidros de La a Tb, cinco bandas $\left(1111,1093,1058,1015\right.$ e $\left.995 \mathrm{~cm}^{-1}\right)$, que nas amostras de Catalão estão agrupadas (embora mostrando ombros nas frequências indicadas) provavelmente devido a características de

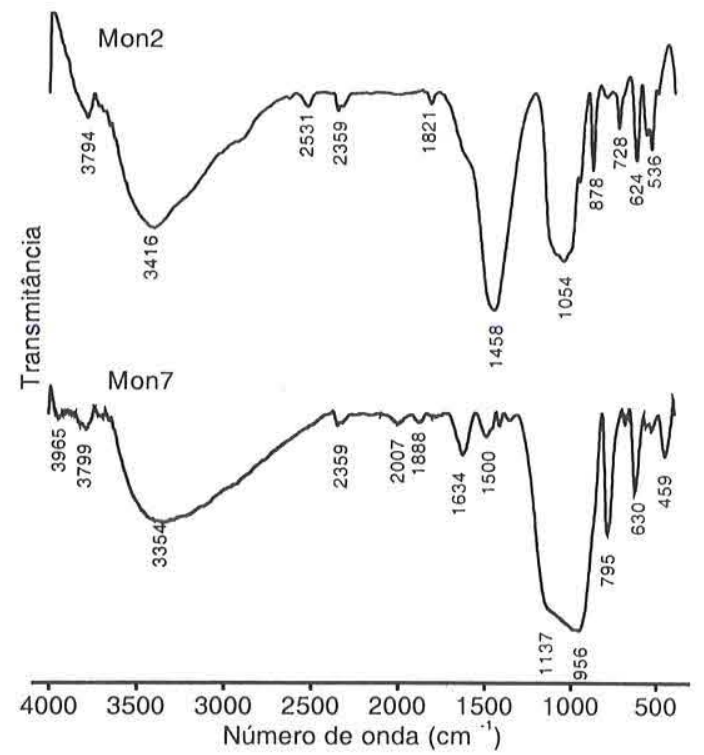

Figura 5 - Espectros de absorção no infravermelho das amostras de monaztita associada ao carbonatito (Mon2) e ao silexito (Mon7). 
baixa cristalinidade. Nesta região, a monazita do silexito apresenta vibrações a $1137 \mathrm{~cm}^{-1}$, enquanto a monazita do carbonatito apresenta vibrações a 1096, 1054 e $1008 \mathrm{~cm}^{-1}$, correspondentes às bandas encontradas pelos autores citados. As vibrações $\boldsymbol{v} \mathbf{1}$ do grupo $\mathrm{PO}_{4}{ }^{3-}$ ocorrem a $955 \mathrm{~cm}^{-1}$ para a monazita estudada por Hezel \& Ross (1966), e foram encontradas, respectivamente, a 956 e 961 $\mathrm{cm}^{-1}$, para a monazita do silexito e do carbonatito. O mesmo trabalho mostra que as vibrações de valência $v 4$ do grupo $\mathrm{PO}_{4}{ }^{3-}$ ocorrem a $625,578,565 \mathrm{e} 538 \mathrm{~cm}^{-1}$, que correspondem às bandas 630 , $573 \mathrm{e} 531 \mathrm{~cm}^{-1}$ para a monazita do silexito e $624,568 \mathrm{e} 536 \mathrm{~cm}^{-1}$ para a monazita do carbonatito. No caso das vibrações de valência $v 2$ do grupo $\mathrm{PO}_{4}{ }^{3-}$, aqueles autores encontraram apenas a banda a $486 \mathrm{~cm}^{-1}$, enquanto a monazita do silexito de Catalão apresentou uma banda a $459 \mathrm{~cm}^{-1}$ e a do carbonatito, uma banda a $500 \mathrm{~cm}^{-1}$. Estas comparações indicam que a monazita de Catalão I apresenta espectros compatíveis com a monazita estudada por Hezel \& Ross (1966).

Adicionalmente, encontram-se nos espectros da monazita de Catalão bandas a $1427 \mathrm{~cm}^{-1}$ e a $1458 \mathrm{~cm}^{-1}$, possivelmente correspondentes ao ânion $\mathrm{CO}_{3}^{2-}$. No caso da monazita do silexito, essas bandas são pouco intensas, podendo representar vestígios dos carbonatos substituídos pela sílica durante a silicificação, ou mesmo uma substituição parcial do ânion $\mathrm{PO}_{4}{ }^{3--}$ por $\mathrm{CO}_{3}{ }^{2-}$. Esta possível presença de $\mathrm{CO}_{3}{ }^{2-}$ na monazita associada ao silexito estaria relacionada a parte da perda de massa verificada na análise térmica. No caso da monazita do carbonatito, essas bandas são bem mais intensas e correspondem certamente às impurezas de carbonato na amostra. A existência de tais impurezas pode ter mascarado possível $\mathrm{CO}_{3}{ }^{2-}$ associado à própria monazita, no caso de existir esta associação.

Por fim, os espectros das amostras estudadas mostram bandas muito largas nas regiões de vibração de $\mathrm{H}_{2} \mathrm{O}$ e $\mathrm{OH}^{\prime}$, respectivamente entre 3100 e $3200 \mathrm{~cm}^{-1}$ e entre 3400 e $3500 \mathrm{~cm}^{-1}$. Apesar de não muito bem diferenciadas, estas bandas são intensas, indicando grau expressivo de presença de água e/ou hidroxila nos materiais que, não obstante, foram secos a $110^{\circ} \mathrm{C}$ antes da preparação. Trata-se, portanto, nesse caso, de água ou hidroxila na estrutura do mineral ou adsorvida, também provavelmente relacionada à

Tabela I - Dados de difração de raios - X da monazita associada ao carbonatito (Mon2) e ao silexito (Mon7), comparados aos da monazita de Peteyanvaara (Bulakh et al. 2000) e da monazita padrão PDF(ICDD) 32-199.

\begin{tabular}{ccccc}
\hline & Mon2 & Mon7 & Peteyanvaara & $\begin{array}{c}\text { PDF } \\
32-199\end{array}$ \\
\hline $\mathrm{a}(\AA)$ & $6.7843(12)$ & $6.8030(13)$ & $6.79(2)$ & 6.8004 \\
$\mathrm{~b}(\AA)$ & $7.0212(11)$ & $7.0169(10)$ & $6.97(1)$ & 7.02231 \\
$\mathrm{c}(\AA)$ & $6.4967(11)$ & $6.4917(9)$ & $6.47(1)$ & 6.4717 \\
$\beta$ & $103.697(16)$ & $103.634(10)$ & $103.55(33)$ & 103.46 \\
vol. $\left(\AA^{3}\right)$ & $300.670(7)$ & $301.160(6)$ & $298(1)$ & 300.6 \\
\hline $\mathrm{R}_{\mathrm{wp}} \%$ & 14.19 & 15.34 & & \\
$\mathrm{R}_{\mathrm{p}} \%$ & 11.28 & 12.06 & & \\
$\chi^{2}$ & 4.202 & 5.180 & & \\
$\mathrm{R}_{\text {Bragy } \%}$ & 4.625 & 4.320 & & \\
\hline
\end{tabular}

perda de massa evidenciada na análise térmica.

Características difratométricas A tabela 1 e a figura 6 apresentam os padrões difratométricos para monazita das duas associações estudadas. As amostras foram obtidas a partir de separação manual, pulverizadas em almofariz de ágata e montadas em lâminas de sílica, por decantação em acetona.

Os difratogramas foram refinados a partir do ajuste do padrão pelo método Rietveld, utilizando o programa computacional GSAS (Larson \& Von Dreele 1994). Os parâmetros liberados durante o refinamento foram: termos do fundo do perfil, fatores de escala, parâmetros de cela unitária e parâmetros do perfil Pseudo-Voigt (largura a meia altura, mistura e simetria) para cada fase. Não foram refinadas as posições atômicas, parâmetros termais e fatores de orientação preferencial.

Previamente foram identificadas as fases minerais associadas à monazita das duas amostras, utilizando uma rotina computacional (EVA) de procura no banco de dados de difração de Raios-X (PDFICDD). Os modelos de estrutura empregados foram: monazita ( $\mathrm{Ni}$
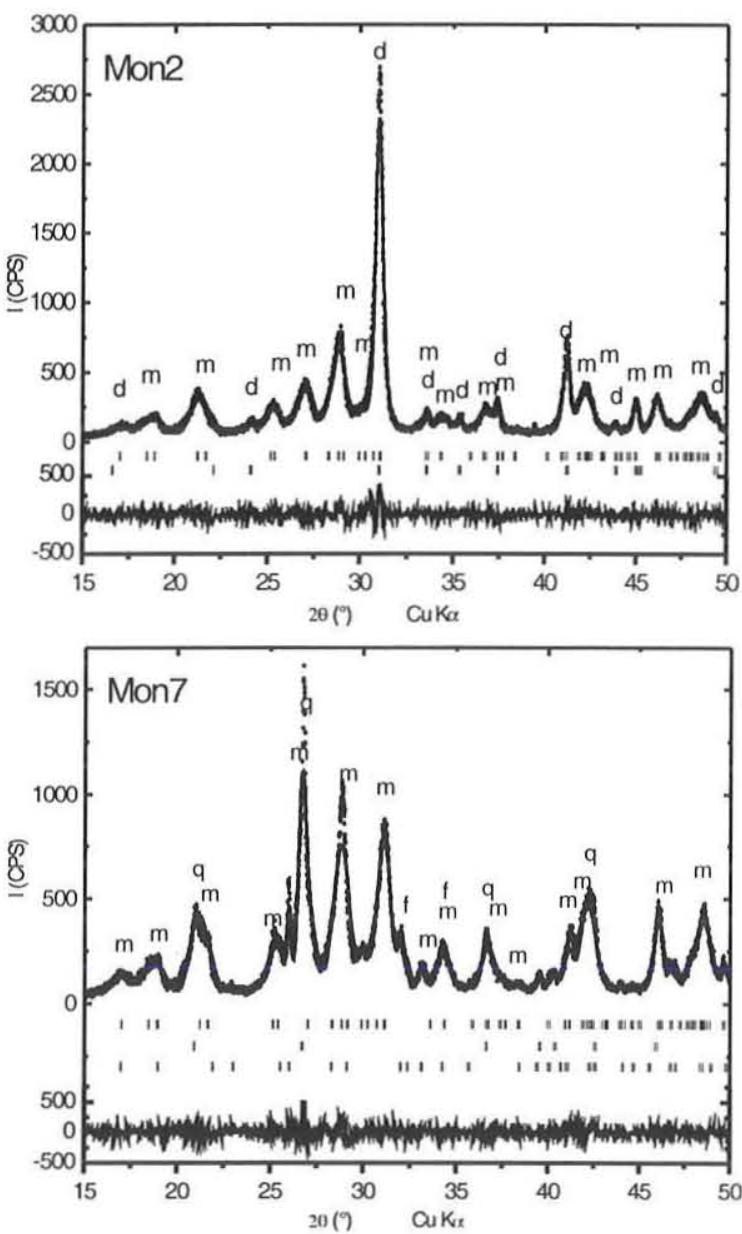

Figura 6 - Difratogramas observado, calculado e residual de amostras de monazita do carbonatito (Mon2) e do silexito (Mon7). O difratograma observado (pontos) e o padrão calculado (linha cheia) estão superpostos. A curva residual é representada abaixo de cada difratograma. $(d$ - dolomita, $m$ monazita, $f$-fluorapatita e $q$ - quartzo). 
et al. 1995), quartzo (Levien et al. 1980), fluorapatita (Hughes et al. 1989) e dolomita (Steinfink \& Sans 1959). O refinamento pelo método de Rietveld confirmou o grupo espacial monoclínico $\mathrm{P} 2 / \mathrm{n}$ para a monazita das duas amostras. Valores de parâmetros de cela dos dois tipos de monazita analisados são próximos entre si e próximos aos valores da monazita padrão PDF(ICDD) 32-199. Os valores dos parâmetros de cela da monazita de ambas amostras estão na tabela 2, bem como os coeficientes estatísticos $R_{w p}, R_{p}, c^{2} e$ $\mathrm{R}_{\mathrm{Bragg}}$ obtidos no final de cada refinamento.

Nota-se na tabela 1 que a intensidade de algumas reflexões difere da intensidade observada no padrão da monazita e na monazita de Peteyanvaara (Bulakh et al. 2000). Estas diferenças podem ser atribuídas a possíveis alterações nas posições atômicas e a substituições por outros elementos nos diferentes sítios cristalinos.

A intensidade relativa das reflexões da monazita das duas amostras são próximas entre si, indicando uma similaridade estrutural. Os perfis das reflexões apresentam um alargamento mostrando possivelmente uma baixa cristalinidade e tamanho reduzido dos cristalitos (Fig. 6).

Os valores elevados dos parâmetros estatísticos (Tabela 2) do refinamento Rietveld apontam para a existência de problemas estruturais em ambas as amostras. Estes podem ser devidos à presença de cátions bivalentes substituindo os ETR, ou ainda pela

Tabela 2 - Parâmetros de cela unitária da monazita de Catalão I calculados por refinamento Rietveld para a monazita associada ao carbonatito (Mon2) e ao silexito (Mon7), comparadas à monazita de Peteyanvaara (Bulakh et al. 2000) e à monazita padrão PDF(ICDD) 32-199.

\begin{tabular}{ccccccccccc}
\hline Amostra & Mon2 & \multicolumn{3}{c}{ Mon7 } & \multicolumn{3}{c}{$\begin{array}{c}\text { Monazita } \\
\text { Peteyanvaara }\end{array}$} & \multicolumn{2}{c}{ PDF(ICDD) } \\
\hline & \multicolumn{1}{c}{ hkl } & $\mathrm{d}(\AA)$ & $\mathrm{I}^{\text {rel }}$ & $\mathrm{d}(\AA)$ & $\mathrm{I}^{\text {rel }}$ & $\mathrm{d}(\AA)$ & $\mathrm{I}^{\text {rel }}$ & $\mathrm{d}(\AA)$ & $\mathrm{I}^{\text {rel }}$ \\
\hline 1 & 0 & -1 & 5,22 & 8 & 5,22 & 9 & 5,20 & 15 & 5,20 & 8 \\
1 & 1 & 0 & 4,81 & 4 & 4,81 & 4 & 4,79 & 7 & 4,81 & 8 \\
0 & 1 & 1 & 4,69 & 9 & 4,69 & 10 & 4,67 & 17 & 4,69 & 14 \\
1 & 1 & -1 & 4,19 & 25 & 4,19 & 20 & 4,18 & 38 & 4,18 & 30 \\
1 & 0 & 1 & 4,10 & 15 & 4,11 & 16 & 4,10 & 19 & 4,11 & 12 \\
1 & 1 & 1 & 3,54 & 10 & 3,54 & 12 & 3,49 & 20 & 3,54 & 12 \\
0 & 2 & 0 & 3,51 & 26 & 3,51 & 29 & - & - & 3,51 & 18 \\
2 & 0 & 0 & 3,30 & 100 & 3,31 & 99 & 3,29 & 60 & 3,31 & 70 \\
1 & 2 & 0 & 3,10 & 97 & 3,10 & 94 & 3,09 & 86 & 3,10 & 100 \\
2 & 1 & 0 & 2,98 & 19 & 2,99 & 16 & 2,99 & 14 & 2,99 & 20 \\
0 & 1 & 2 & 2,88 & 85 & 2,88 & 85 & 2,87 & 100 & 2,87 & 70 \\
2 & 0 & -2 & 2,61 & 52 & 2,61 & 59 & 2,60 & 19 & 2,60 & 20 \\
1 & 1 & 2 & 2,45 & 15 & 2,45 & 16 & - & - & 2,45 & 12 \\
2 & 1 & -2 & 2,45 & 26 & 2,45 & 24 & 2,44 & 20 & 2,44 & 18 \\
2 & 2 & 0 & 2,40 & 7 & 2,41 & 9 & - & - & 2,41 & 8 \\
0 & 3 & 1 & 2,19 & 49 & 2,19 & 53 & 2,18 & 20 & 2,20 & 30 \\
1 & 0 & -3 & 2,16 & 87 & 2,16 & 100 & 2,15 & 29 & 2,15 & 30 \\
3 & 1 & -1 & 2,14 & 51 & 2,14 & 47 & 2,13 & 25 & 2,14 & 45 \\
2 & 2 & 1 & 2,13 & 44 & 2,13 & 43 & - & - & 2,13 & 30 \\
2 & 1 & 2 & 1,97 & 82 & 1,97 & 88 & 1,96 & 29 & 1,97 & 45 \\
3 & 0 & 1 & 1,94 & 40 & 1,94 & 38 & - & - & 1,94 & 12 \\
2 & 3 & -1 & 1,90 & 36 & 1,90 & 34 & - & - & 1,90 & 25 \\
1 & 0 & 3 & 1,88 & 22 & 1,88 & 24 & 1,87 & 18 & 1,88 & 40 \\
3 & 2 & 0 & 1,86 & 43 & 1,87 & 37 & 1,87 & 20 & 1,87 & 30 \\
0 & 2 & 3 & 1,80 & 15 & 1,80 & 21 & 1,80 & 8 & 1,80 & 12 \\
\hline & & & & & & & & & &
\end{tabular}

ocupação incompleta do sítio aniônico (ver adiante).

Composição química A determinação da composição química por microssonda eletrônica de materias microcristalinos, porosos e mais ou menos hidratados apresenta problemas analíticos bem conhecidos, entre os quais o mais comum é a soma total dos óxidos correspondentes a todos os elementos presentes ficar significativamente abaixo de $100 \%$. No entanto, o cálculo da fórmula estrutural de tais minerais mostra resultados compatíveis, de modo que, dentro de certos limites, as análises podem ser consideradas confiáveis. Para o presente trabalho, foram analisados mais de 300 pontos, mas só foram utilizados cerca de 150 , tendo sido usado como critério de corte a soma total dos óxidos maior que $80 \%$. Para cada amostra, são apresentados o número de pontos analisados e os valores médios, máximos e mínimos para cada óxido dosado nas amostras Mon1, Mon2, Mon3, Mon4, Mon5 e Mon6, correspondentes às profundidades de $1 \mathrm{~m}, 24 \mathrm{~m}, 72 \mathrm{~m}, 106 \mathrm{~m}, 152 \mathrm{~m}, \mathrm{e} 220$ $\mathrm{m}$ dos furos de sondagem no carbonatito, respectivamente, e nas amostras de silexito, Mon7 (Tabela 3).

As amostras de monazita associadas ao carbonatito mostraram uma certa variação química e por esse motivo os resultados aparecem discriminados em função da profundidade do furo de onde foram retiradas. As amostras de monazita associadas ao silexito, ao contrário, embora apresentassem variação de cor macro e microscopicamente, mostraram-se quimicamente muito mais homogêneas e os resultados correspondentes são apresentados sob a denominação de Mon7.

As amostras de monazita estudadas revelaram baixos conteúdos em ETRP e elevados conteúdos em ETRL, o que é característico desse mineral. O Ce predomina, vindo, em seguida o La e o Nd. $\mathrm{Pr}, \mathrm{Sm}, \mathrm{Gd}$ e Dy estão presentes em quantidades bem subordinadas. Os demais ETR não foram dosados. Foram também determinados $\mathrm{Al}, \mathrm{Y}, \mathrm{U}$ e Th, e os resultados ficaram próximos do limite de detecção. Apenas na amostra Monl foram encontrados teores consideráveis de Th (até 2,47\% $\mathrm{ThO}_{2}$ ). No entanto, como se trata de resultados muito variáveis para os diferentes pontos analisados sobre a mesma lâmina, estes foram interpretados como devido a possíveis impurezas, não tendo sido, portanto, atribuídos à monazita no cálculo da fórmula estrutural.

Uma característica marcante da monazita de Catalão I é a presença importante de íons bivalentes, representados por $\mathrm{Ca}, \mathrm{Sr}$ e $\mathrm{Ba}$. $\mathrm{Mn}$ e Fe também foram dosados, sendo os resultados nulos para o primeiro elemento, e muito próximos do limite de detecção para o segundo. $\mathrm{SrO}$ e $\mathrm{CaO}$ ocorrem em maiores concentrações, sempre com predomínio do primeiro sobre o segundo, exceto na amostra Mon2, onde esses óxidos estão presentes aproximadamente na mesma quantidade. $\mathrm{O} \mathrm{BaO}$ é bem menos abundante, ocorrendo geralmente em quantidades próximas a $1 \%$, mas podendo atingir quase $3 \%$. A substituição dos ETR por $\mathrm{Ca}^{2+}$ é explicada pela semelhança de raio e de coordenação. Os ETR na monazita encontramse em coordenação 8; nessa coordenação os raios iônicos dos ETRL estão entre $1,1 \AA$ e $1,2 \AA$, assim como o raio do $\mathrm{Ca}^{2+}$. Por razões de equilíbrio de carga elétrica deve haver simultaneamente a ocorrência de substituições acopladas (Miyawaki \& Nakai, 1996) de íons tetravalentes, como por exemplo o $\mathrm{Th}^{4+}\left(2 \mathrm{ETR}^{3+} \leftrightarrow \mathrm{Ca}^{2+}\right.$ $\left.+\mathrm{Th}^{4+}\right)$, hexavalentes como o $\mathrm{S}^{6+}\left(\mathrm{Ce}^{3+}+\mathrm{P}^{5+} \ll \mathrm{Ca}^{2+}+\mathrm{S}^{6+}\right)$, ou de substituições acompanhando vacâncias $\left(3 \mathrm{Ca}^{2+} \leftrightarrow 2 \mathrm{ETR}^{3+}+\bullet\right.$, ou $\left.3 \mathrm{Ce}^{3+}+3 \mathrm{PO}_{4}^{3-} \leftrightarrow 3 \mathrm{Ca}^{2+}+2 \mathrm{PO}_{4}^{3-}+1 \cdot\right)$.

A incorporação do $\mathrm{Sr}^{2+}$ e do $\mathrm{Ba}^{2+}$ é mais complicada, pois esses íons possuem raios muito mais elevados $\left(\mathrm{r} \mathrm{Sr}^{2+}=1,33 \AA\right.$; $\mathrm{r} \mathrm{Ba}^{2+}=$ $1,50 \AA$ A). No entanto, a persistência dos teores nestes elementos 
Tabela 3 - Composição química (valores médios, mínimos e máximos) média para a monazita associada ao carbonatito (Monl a Mon6) e ao silexito (Mon7), expressa em porcentagem em peso dos óxidos, obtida em análises por microssonda eletrônica.

\begin{tabular}{|c|c|c|c|c|c|c|c|c|c|c|c|c|c|c|c|c|c|c|c|c|c|}
\hline & \multicolumn{3}{|c|}{ Monl $(n=6)$} & \multicolumn{3}{|c|}{ Mon $2(n=17)$} & \multicolumn{3}{|c|}{ Mon3 $(n=13)$} & \multicolumn{3}{|c|}{ Mon4 $(n=16)$} & \multicolumn{3}{|c|}{ Mons $(n=12)$} & \multicolumn{3}{|c|}{ Mon6 $(n=7)$} & \multicolumn{3}{|c|}{ Mon $7(n=73)$} \\
\hline & média & máx & $\mathrm{m}$ in & média & máx & mín & média & máx & mín & média & máx & $\mathrm{m}$ in & média & máx & $\mathrm{min}$ & média & máx & mín & média & máx & mín \\
\hline $\mathrm{Al}_{2} \mathrm{O}_{3}$ & 0,00 & 0.00 & 0.00 & 0.01 & 0,06 & 0,00 & 0,02 & 0,06 & 0,00 & 0.00 & 0,02 & 0,00 & 0.00 & 0,04 & 0,00 & 0,00 & 0.00 & 0,00 & 0.02 & 0.10 & 0.00 \\
\hline $\mathrm{SiO}_{2}$ & 0,36 & 0,56 & 0.13 & 0,41 & 0.65 & 0.08 & 0,60 & 0.99 & 0.20 & 0.19 & 0,45 & 0,04 & 0,27 & 0,76 & 0,07 & 0,14 & 0.39 & 0,05 & 0,05 & 0.50 & 0,00 \\
\hline $\mathrm{P}_{2} \mathrm{O}_{5}$ & 26,76 & 27,70 & 26.12 & 27.47 & 28.29 & 25.93 & 26,37 & 28.47 & 24.82 & 25,97 & 27,77 & 23,33 & 26,03 & 27,20 & 24,07 & 26.84 & 29.20 & 25.56 & 26,21 & 28.72 & 24,03 \\
\hline $\mathrm{CaO}$ & 2.31 & 2.77 & 1.74 & 1.59 & 1,84 & 1,44 & 1.82 & 2.10 & 1.58 & 1,66 & 2,33 & 1.44 & 1,89 & 2,23 & 1.59 & 1.58 & 1,83 & 1,45 & 2,14 & 2.70 & 1.83 \\
\hline $\mathrm{MnO}$ & 0.00 & 0.00 & 0,00 & 0,00 & 0.00 & 0.00 & 0,00 & 0.00 & 0,00 & 0.00 & 0.00 & 0,00 & 0,00 & 0.00 & 0.00 & 0,00 & 0.00 & 0,00 & 0.00 & 0.03 & 0.00 \\
\hline $\mathrm{SrO}$ & 6,27 & 7,25 & 4,88 & 1,55 & 1,87 & 1,12 & 2,92 & 3,62 & 2,41 & 3.50 & 4,04 & 3,13 & 2,48 & 2.74 & 2,10 & 3,39 & 3,87 & 3,11 & 3,85 & 4,62 & 2.96 \\
\hline $\mathrm{Y}_{2} \mathrm{O}_{1}$ & 0.00 & 0,00 & 0,00 & 0.04 & 0.17 & 0.00 & 0.02 & 0,12 & 0.00 & 0,00 & 0,00 & 0.00 & 0,01 & 0,06 & 0,00 & 0,00 & 0.00 & 0.00 & 0,00 & 0.00 & 0,00 \\
\hline $\mathrm{BaO}$ & 0,37 & 0,68 & 0,06 & 0.63 & 0.93 & 0,33 & 1,19 & 1,64 & 0,71 & 0,85 & 1,16 & 0,33 & 1,39 & 2,05 & 0,46 & 1.16 & 1,45 & 0,95 & 1.93 & 2,93 & 1.34 \\
\hline $\mathrm{L}_{\mathrm{a}_{2}} \mathrm{O}_{3}$ & 11.18 & 11.64 & 10.90 & 16,74 & 19.79 & 14,64 & 11,98 & 13.36 & 10,64 & 22,89 & 24.73 & 21,37 & 13.91 & 15.47 & 12,11 & 14,11 & 14,65 & 13,23 & 20.49 & 23,41 & 18.14 \\
\hline $\mathrm{Ce}_{2} \mathrm{O}$ & 27.09 & 27,73 & 25,86 & 30,14 & 31,46 & 28,48 & 31,42 & 32,86 & 27,86 & 26,21 & 27,88 & 24,70 & 28.95 & 30,74 & 24,89 & 30,20 & 31,78 & 29,44 & 25,03 & 28.48 & 21.75 \\
\hline $\mathrm{Pr}_{2} \mathrm{O}_{3}$ & 3.01 & 3,39 & 2.38 & 2,87 & 3,39 & 2.29 & 3.03 & 3,56 & 2,39 & 1,71 & 2,15 & 1,14 & 3,15 & 3,86 & 2,49 & 2,98 & 3,58 & 2,55 & 1,50 & 2.18 & 0.71 \\
\hline $\mathrm{Nd} ; \mathrm{O}_{3}$ & 10.68 & 11,41 & 10.09 & 8.89 & 10,34 & 7,41 & 9,40 & 11.03 & 7,57 & 4.16 & 4,80 & 3,29 & 11,32 & 12,73 & 9,37 & 10.54 & 11.13 & 9,90 & 4.39 & 5.25 & 2.91 \\
\hline $\mathrm{Gd}_{2} \mathrm{O}_{3}$ & 0.45 & 0.96 & 0,00 & 0.18 & 0.91 & 0.00 & 0,13 & 0.31 & 0,00 & 0.11 & 0,40 & 0,00 & 0.28 & 0.67 & 0,00 & 0,11 & 0,48 & 0,00 & 0.08 & 0.71 & 0,00 \\
\hline $\mathrm{Dy}_{2} \mathrm{O}_{3}$ & 0.10 & 0,31 & 0,00 & 0.05 & 0,24 & 0.00 & 0,03 & 0,32 & 0.00 & 0,01 & 0,10 & 0,00 & 0,03 & 0,11 & 0,00 & 0,01 & 0.07 & 0,00 & 0.02 & 0.16 & 0.00 \\
\hline $\mathrm{ThO}_{2}$ & 1,25 & 2,47 & 0,00 & 0,03 & 0.17 & 0,00 & 0,02 & 0.10 & 0,00 & 0,04 & 0,23 & 0,00 & 0,02 & 0.08 & 0.00 & 0,02 & 0,11 & 0,00 & 0.03 & 0.24 & 0.00 \\
\hline $10:$ & 0.08 & 0,26 & 0.00 & 0.04 & 0,23 & 0.00 & 0,03 & 0.17 & 0.00 & 0,07 & 0,19 & 0,00 & 0,05 & 0,20 & 0.00 & 0,05 & 0.16 & 0.00 & 0,05 & 0.26 & 0.00 \\
\hline lotal & 91,74 & 93,06 & 90,07 & 93,53 & 96,27 & 89.54 & 91.98 & 96.97 & 86.46 & 90,03 & 95,43 & 83.58 & 92,73 & 86,39 & 85,50 & 94,13 & 100,09 & 92.27 & 85,54 & 93.83 & 80,24 \\
\hline REE & 54,04 & 54.82 & 51.52 & 60,34 & 62.43 & 57,46 & 57.54 & 60.26 & 53,42 & 56.32 & 59,64 & 52,58 & 59,18 & 62.27 & 54,12 & 59,50 & 62,60 & 57.94 & 51.41 & 56.15 & 47.53 \\
\hline
\end{tabular}

nas análises por ME indicam que eles não estão em inclusões mas sim estão presentes na estrutura do mineral. Monazita com substituição dos ETR por $\mathrm{Sr}^{2+}$, acoplada a substituição por $\mathrm{Th}^{4+}$, foi descrita na Rússia em carbonatitos e em kimberlitos (Chakhmouradian \& Mitchell 1998). Nos complexos de Kandaguba e Vuoriyarvi, na Península de Kola, Bulakh et al. (2000) verificaram a presença de até $4,36 \%$ de $\mathrm{SrO}$ e até $5,77 \%$ de $\mathrm{ThO}_{2}$. Além das ocorrências na Rússia, em diques carbonatíticos na Argentina foi registrada a presença de monazita com até $3,1 \%$ de $\mathrm{SrO}$; nesse caso, também, o aumento do teor de $\mathrm{SrO}$ é acompanhado do aumento de $\mathrm{ThO}_{2}$ (Del Blanco et al. 1998). Sobre a presença de $\mathrm{Ba}^{2+}$ em monazita, porém, não foram encontradas referências documentadas. Traversa et al. (2001), em estudo sobre as rochas do complexo carbonatítico de Araxá (Brasil), mencionam que a monazita lá existente contém altos teores em $\mathrm{SrO}$ e $\mathrm{BaO}$, mas não apresentaram valores.

Os óxidos $\mathrm{P}_{2} \mathrm{O}_{5}$ e $\mathrm{SiO}_{2}$ completam as análises. Os teores de $\mathrm{P}_{2} \mathrm{O}_{5}$ situam-se entre 26,0 e $27,5 \%$ e os de $\mathrm{SiO}_{2}$, entre 0,05 e $0,60 \%$. Os totais perfazem valores entre 85,5 e $94,1 \%$.

No cálculo da fórmula estrutural da monazita considerou-se os seguintes elementos: $\mathrm{Si}, \mathrm{P}, \mathrm{Ca}, \mathrm{Sr}, \mathrm{Ba}, \mathrm{La}, \mathrm{Ce}, \mathrm{Pr}, \mathrm{Nd}$ e Sm. Os resultados, tomando como referência $\mathrm{O}=4 \mathrm{e}$, portanto, o total para a posição aniônica $(\mathrm{P}+\mathrm{Si})=1$, mostraram que sempre há excesso de íons na posição catiônica (bivalentes + trivalentes $>1$ ) e, conseqüentemente, excesso de carga positiva, como mostram os valores médios na tabela 4. Esse excesso nas posições catiônicas pode também ser interpretado como vacâncias nas posições aniônicas, o que fica evidente quando a fórmula estrutural é calculada considerando a soma de cátions $=1$ (Tabela 5).

$\mathrm{Na}$ ausência de cátions tetravalentes ou hexavalentes, e na presença de íons trivalentes, bivalentes e $\mathrm{Si}^{4+}$, o modelo de substituições proposto é o seguinte:

$$
3 \text { Trivalentes }+3 \mathrm{PO}_{4}{ }^{3 \cdot} \leftrightarrow 3 \text { Bivalentes }+2 \mathrm{PO}_{4}{ }^{3 \cdot}+1 \cdot
$$

3 Trivalentes $+3 \mathrm{PO}_{4}{ }^{3 \cdot} \leftrightarrow 3$ Trivalentes $+9 / 4 \mathrm{SiO}_{4}{ }^{4 \cdot}+3 / 4 \cdot$

3 Trivalentes $+3 \mathrm{PO}_{4}{ }^{3 \cdot} \leftrightarrow 3$ Bivalentes $+3 / 2 \mathrm{SiO}_{4}{ }^{4 \cdot}+3 / 2 \cdot$

Adicionalmente, foram incluídos na posição aniônica hidroxilas tetraédricas $\left(\mathrm{H}_{4} \mathrm{O}_{4}\right)^{-4} \mathrm{em}$ proporção que satisfizesse o equilíbrio de cargas $(0$ a $4 \%)$. Esses radicais, cuja presença na monazita pode ser justificada pelos resultados de ATD-TG e IV, contribuem para o equilíbrio das cargas e para a manutenção da estrutura. A inclusão de $\left(\mathrm{H}_{4} \mathrm{O}_{4}\right)^{4}$, além do $\mathrm{PO}_{4}{ }^{3 \cdot}$ e $\mathrm{SiO}_{4}{ }^{4-}$, nos sítios aniônicos foi proposta por Van Wambeke (1971) para a crandallita e outros fosfatos. Com a inclusão desses radicais, as vacâncias nas posições aniônicas alcançaram entre 3 e $6 \%$ (Tabela 5). A fórmula estrutural da monazita pode, assim, ser representada pela expressão geral:

$\left[(\text { Bivalentes) (Trivalentes) }]_{1,0}\left[\left(\mathrm{PO}_{4}\right)\left(\mathrm{SiO}_{4}\right)\left(\mathrm{H}_{4} \mathrm{O}_{4}\right) \cdot\right]_{1,0}\right.$

Nas figuras 7 e 8 estão projetados os resultados para todos os pontos analisados em cada uma das amostras. Além da variabilidade química de amostra para amostra, os resultados indicam que há variação composicional de ponto a ponto, numa mesma amostra. Não foi notado, entretanto, pelas análises microlocalizadas, variação sistemática de teores, configurando zoneamento composicional nos grãos analisados, embora algumas imagens em elétrons retroespalhados ao MEV sugiram zoneamento.

De modo geral, as 7 amostras analisadas são semelhantes quimicamente. No detalhe, no entanto, é possível discernir algumas diferenças. Para as amostras de monazita associada ao carbonatito (Fig. 7), o diagrama triangular P-bivalentestrivalentes indica a existência de 3 famílias, muito bem individualizadas: Mon1, Mon2 e (Mon3+Mon4+Mon5+Mon6). Mon 1 é a amostra mais rica em bivalentes, Mon2, a mais pobre; (Mon3+Mon4+Mon5+Mon6) estão em posição intemediária. Para maior detalhe, foram construídos os diagramas triangulares $\mathrm{Ca}-\mathrm{Sr}$ $\mathrm{Ba}$ e La-Ce-(Nd+Pr+Sm). No primeiro deles fica evidente que Mon 1 é a amostra mais rica em $\mathrm{Sr}$, e Mon2, a mais pobre; 
Tabela 4 - Fórmula estrutural média para a monazita associada ao carbonatito (Mon1 a Mon6) e ao silexito(Mon7), em número de átomos p.f.u., calculada a partir das médias dos dados das análises por microssonda eletrônica, na base $O=4$. ( $n=n^{2}$ de análises)

\begin{tabular}{c|ccccccc} 
& $\begin{array}{c}\text { Mon1 } \\
(\mathrm{n}=6)\end{array}$ & $\begin{array}{c}\text { Mon2 } \\
(\mathrm{n}=17)\end{array}$ & $\begin{array}{c}\text { Mon3 } \\
(\mathrm{n}=13)\end{array}$ & $\begin{array}{c}\text { Mon4 } \\
(\mathrm{n}=16)\end{array}$ & $\begin{array}{c}\text { Mon5 } \\
(\mathrm{n}=12)\end{array}$ & $\begin{array}{c}\text { Mon6 } \\
(\mathrm{n}=7)\end{array}$ & $\begin{array}{c}\text { Mon7 } \\
(\mathrm{n}=73)\end{array}$ \\
\hline $\mathrm{Si}$ & 0,015 & 0,026 & 0,026 & 0,009 & 0,013 & 0,010 & 0,001 \\
$\mathrm{P}$ & 0,986 & 0,998 & 0,971 & 0,979 & 0,962 & 0,969 & 0,997 \\
$\mathrm{Ca}$ & 0,108 & 0,073 & 0,085 & 0,079 & 0,095 & 0,077 & 0,103 \\
$\mathrm{Sr}$ & 0,158 & 0,038 & 0,074 & 0,090 & 0,063 & 0,086 & 0,100 \\
$\mathrm{Ba}$ & 0,006 & 0,011 & 0,020 & 0,015 & 0,024 & 0,021 & 0,037 \\
$\mathrm{La}$ & 0,180 & 0,270 & 0,192 & 0,376 & 0,225 & 0,222 & 0,340 \\
$\mathrm{Ce}$ & 0,432 & 0,472 & 0,500 & 0,427 & 0,465 & 0,475 & 0,412 \\
$\mathrm{Pr}$ & 0,048 & 0,043 & 0,048 & 0,028 & 0,050 & 0,048 & 0,025 \\
$\mathrm{Nd}$ & 0,166 & 0,132 & 0,146 & 0,066 & 0,176 & 0,163 & 0,070 \\
$\mathrm{Sm}$ & 0,015 & 0,007 & 0,008 & 0,003 & 0,010 & 0,008 & 0,000 \\
\hline bi & 0,272 & 0,121 & 0,179 & 0,185 & 0,182 & 0,184 & 0,240 \\
tri & 0,841 & 0,923 & 0,895 & 0,900 & 0.926 & 0,915 & 0,847 \\
\hline bi+tri & 1,113 & 1,034 & 1,073 & 1,085 & 1,108 & 1,099 & 1,087 \\
P+Si & 1,001 & 1,024 & 0,997 & 0,988 & 0,975 & 0,979 & 0,998 \\
\hline carga & 0,047 & $-0,086$ & 0,024 & 0,096 & 0,205 & 0,167 & 0,026 \\
\hline
\end{tabular}

(Mon3+Mon4+Mon5+Mon6) ficam, de novo, em situação intermediária. Com relação aos trivalentes, a situação é menos clara. Monl é amostra bem pobre em La, enquanto Mon2 apresenta maiores teores nesse elemento. As demais amostras estão em situação intermediária entre Monl e Mon2, com exceção de Mon4 que é a mais enriquecida em La entre as amostras de monazita associada a carbonatito. Os diagramas binários da Figura 8 mostram que, em cada amostra, os pontos analisados dispõem-se em relações lineares, compatíveis com as seguintes substituições acopladas:

$$
\mathrm{Ca}+\mathrm{Ba} \leftrightarrow 2 \mathrm{Sr}
$$

$\mathrm{Ce}+\mathrm{Pr}+\mathrm{Nd}+\mathrm{Sm} \leftrightarrow 3 \mathrm{La}$

Para as amostras de monazita associada ao silexito, a variação química é muito menor. Nos diagramas triangulares (Fig. 7) o conjunto de pontos analisados distribui-se em área bem restrita, indicando maior uniformidade composicional. O diagrama binário $2 \mathrm{Sr}-\mathrm{Ca}+\mathrm{Ba}$ (Fig. 8) mostra os 73 pontos analisados muito concentrados, apontando para uma notável homogeneidade composicional com relação aos elementos bivalentes. Para os cátions trivalentes, há maior variação, consistente com o mesmo esquema de substituição acoplada acima mencionado.

CONSIDERAÇÕES FINAIS A monazita de Catalão I apresenta características incomuns em seus aspectos morfológicos, químicos e cristaloquímicos. Ocorre associada ao carbonatito e às rochas silicificadas, em agregados criptocristalinos muito porosos e descontínuos, não sendo possível individualizar os cristais nem ao MO nem ao MEV; este caráter dificulta a determinação de suas características ópticas e limita a possibilidade da aplicação de processos industriais de grande escala para seu aproveitamento econômico. As relações espaciais verificadas nos estudos morfológicos de macro e micro escala demonstraram que a monazita associada aos carbonatitos é tardia em relação aos
Tabela 5 - Fórmula estrutural média para a monazita associada ao carbonatito (Mon I a Mon6) e ao silexito (Mon7), em número de átomos p.f.u., calculada a partir das médias dos dados das análises por microssonda eletrônica, na base da soma de cátions $=1 .\left(n=n^{\varrho}\right.$ de análises $)$

\begin{tabular}{c|ccccccc} 
& $\begin{array}{c}\text { Mon1 } \\
(\mathrm{n}=6)\end{array}$ & $\begin{array}{c}\text { Mon2 } \\
(\mathrm{n}=17)\end{array}$ & $\begin{array}{c}\text { Mon3 } \\
(\mathrm{n}=13)\end{array}$ & $\begin{array}{c}\text { Mon4 } \\
(\mathrm{n}=16)\end{array}$ & $\begin{array}{c}\text { Mon5 } \\
(\mathrm{n}=12)\end{array}$ & $\begin{array}{c}\text { Mon6 } \\
(\mathrm{n}=7)\end{array}$ & $\begin{array}{c}\text { Mon7 } \\
(\mathrm{n}=73)\end{array}$ \\
\hline $\mathrm{Si}$ & 0,014 & 0,017 & 0,024 & 0,008 & 0.013 & 0.005 & 0,002 \\
$\mathrm{P}$ & 0,887 & 0,955 & 0,905 & 0,903 & 0,876 & 0,895 & 0,921 \\
$\mathrm{Ca}$ & 0,097 & 0,069 & 0,079 & 0,073 & 0,081 & 0,066 & 0,095 \\
$\mathrm{Sr}$ & 0,142 & 0,036 & 0,069 & 0,083 & 0,057 & 0.078 & 0,093 \\
$\mathrm{Ba}$ & 0,006 & 0,011 & 0,019 & 0,014 & 0.022 & 0,018 & 0,032 \\
$\mathrm{La}$ & 0,161 & 0,258 & 0,179 & 0,347 & 0.204 & 0,205 & 0,314 \\
$\mathrm{Ce}$ & 0.388 & 0,452 & 0,466 & 0,394 & 0,421 & 0.435 & 0,379 \\
$\mathrm{Pr}$ & 0,043 & 0,041 & 0,045 & 0,025 & 0,046 & 0.043 & 0,022 \\
$\mathrm{Nd}$ & 0,149 & 0,126 & 0,136 & 0,061 & 0,160 & 0,148 & 0,065 \\
$\mathrm{Sm}$ & 0,014 & 0,006 & 0,008 & 0,003 & 0,009 & 0,007 & 0,000 \\
\hline bi & 0,245 & 0,116 & 0,167 & 0,170 & 0,160 & 0,162 & 0.220 \\
tri & 0,755 & 0,884 & 0,833 & 0,830 & 0,840 & 0,838 & 0,780 \\
bi+tri & 1,000 & 1,000 & 1,000 & 1,000 & 0.999 & 1,000 & 1,000 \\
\hline P+Si & 0,901 & 0,972 & 0,929 & 0,911 & 0,889 & 0,904 & 0,923 \\
\hline $\mathrm{H}_{4} \mathrm{O}_{4}$ & 0,010 & 0,000 & 0,006 & 0,023 & 0,040 & 0,033 & 0,002 \\
\hline carga & $-0,001$ & $-0,049$ & 0,000 & $-0,002$ & $-0,002$ & 0,001 & 0,001 \\
\hline vacân & 0,089 & 0,028 & 0.065 & 0,066 & 0,071 & 0,067 & 0.075 \\
cias & & & & & & & \\
\hline & & & & & & &
\end{tabular}

carbonatos e à apatita e, no caso do silexito, é contemporânea ao quartzo, indicando origem pelo intenso hidrotermalismo - sobretudo a silicificação - que afetou o complexo nas fases finais do evento magmático (Baecker 1983). Apesar de parte das amostras estarem em material intensamente intemperizado, a monazita apresenta apenas raras e localizadas evidências de alteração em cerianita e em gorceixita.

Sua composição química é incomum, caracterizada pela presença de $\mathrm{Ca}$, Sr e Ba, e pela ausência de Th e U. Além disso, as análises por espectroscopia no infravermelho indicam a possibilidade da presença de água na estrutura, também sugerida pelas análises térmicas. Os dados químicos mostraram que nos sítios catiônicos há substituições acopladas entre os elementos divalentes e entre os trivalentes. Nas posições aniônicas, além do $\mathrm{PO}_{4}{ }^{3-}$ estão presentes o $\mathrm{SiO}_{4}{ }^{4-}$ e o radical $\left(\mathrm{H}_{4} \mathrm{O}_{4}\right)^{4}$. As fórmulas estruturais calculadas indicam também a existência de vacâncias nas posições aniônicas. Essas peculiaridades não afetaram a estrutura do mineral, cujos parâmetros de cela unitária são próximos aos da monazita padrão. No entanto, o estudo dos difratogramas e seu refinamento pelo método de Rietveld indicam que a monazita de Catalão é mal cristalizada, provavelmente com cristalitos com dimensões muito pequenas. Essas características são também sugeridas pelos espectros IV.

Agradecimentos À FAPESP (processos 95/6685-5 e 96/7868-9), CNPq (processo 303796/86-3) e CAPES-COFECUB, (processos 

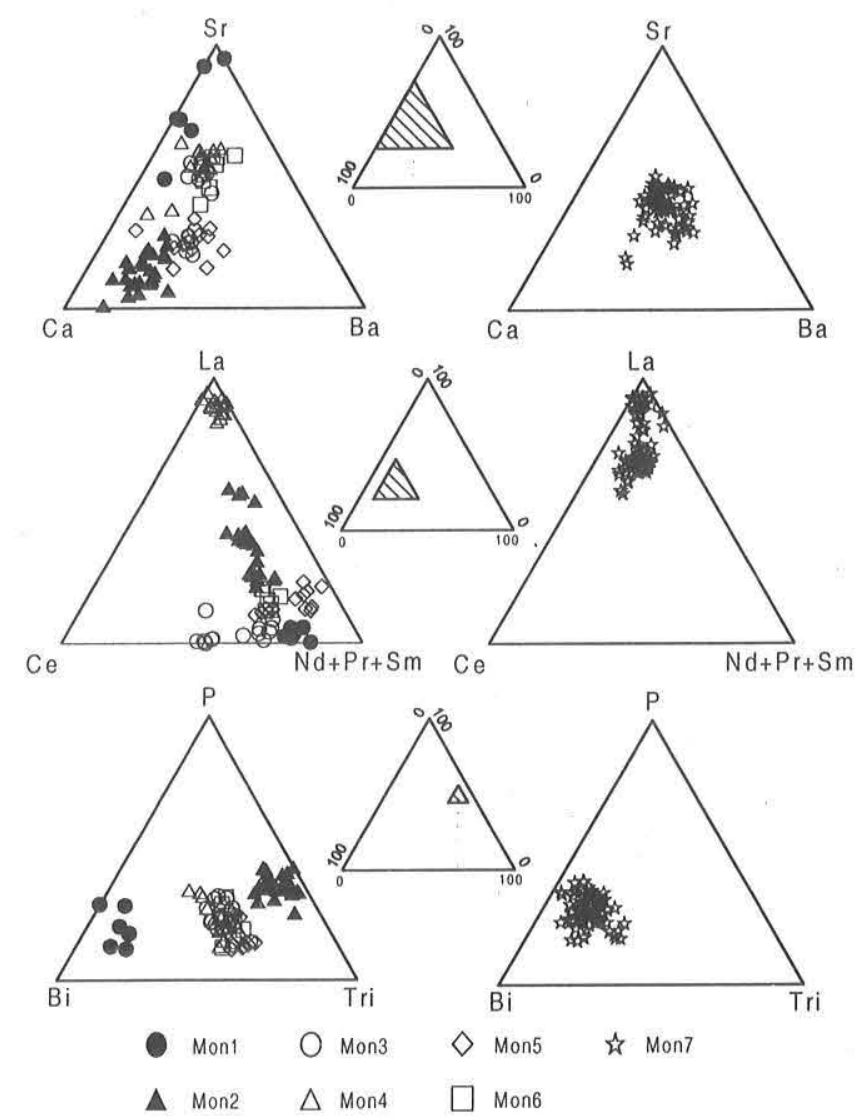

Figura 7 - Diagramas P x Bi x Tri (fósforo, cátions bivalentes $e$ cátions trivalentes em número de átomos p.f.u., segundo cálculo de fórmula estrutural na base 1 cátion, a partir dos dados de análises por ME) de monazita associada ao carbonatito (esquerda) e ao silexito (direita) de Catalão I (GO).
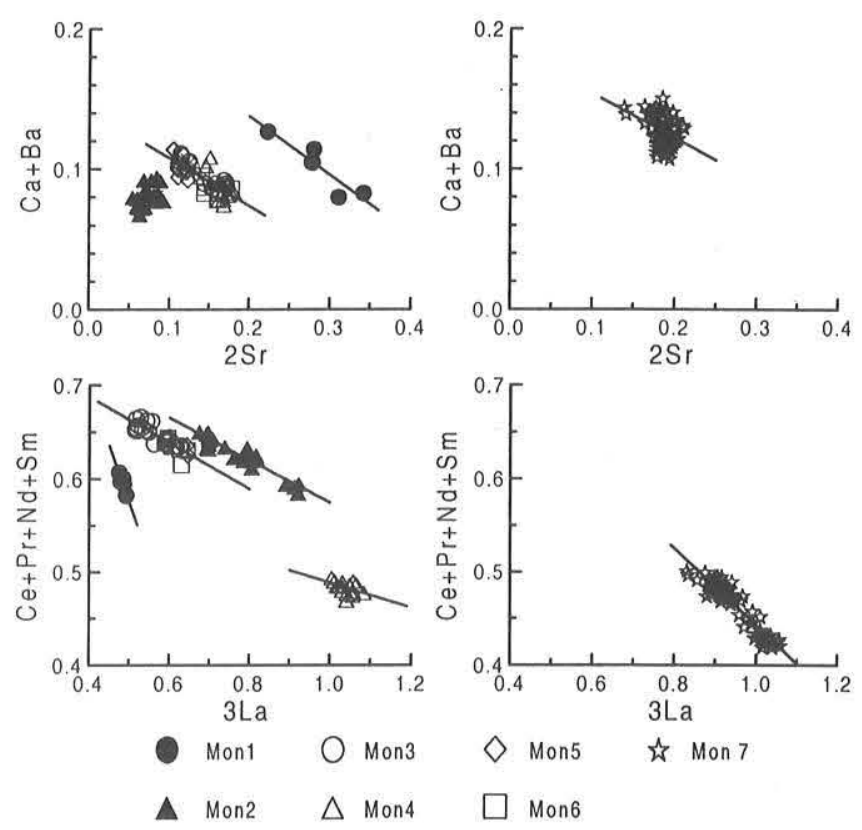

Figura 8 - Gráficos binários envolvendo a composição catiônica e o P para a monazita associada ao carbonatito (esquerda) e ao silexito (direita) de Catalão I (GO).

169/95 e 309/00 - II). A Flávio M. de Carvalho pelo auxílio nos trabalhos por DRX, ao geólogo Carlos Cordeiro Ribeiro pelo acompanhamento nos trabalhos de campo e pelas informações sobre a geologia do complexo, bem como à Ultrafértil S.A. pela autorização de acesso á área e amostragem dos materiais. Aos revisores da RBG pela sugestões ao manuscrito.

\section{Referências}

Araújo D.P. de \& Gaspar J.C. 1992. Química mineral dos carbonatitos e rochas associadas de Catalão I, GO. In: SBG, Congr. Bras. Geol., 37, Anais, São Paulo, 90-91.

Baecker M.L. 1983. A mineralização de nióbio do solo residual e a petrografia das rochas ultramáfico-alcalinas do domo de Catalão I, Goiás. Dissertação de Mestrado, Instituto de Geociências, Universidade de Brasília, 113p.

Bulakh A.G., Nesterov A.R., Zaitsev A.N., Pilipiuk A.N., Wall A.F., Kirillov A.S. 2000. Sulfur-containig monazite-(Ce) from late-stage mineral assemblages at the Kandaguba and Vuoriyarvi carbonatite complexes, Kola peninsula, Russia. N. Jb. Miner: Mh., 5:217-233.

Carvalho W.T. 1974. Aspectos geológicos e petrográficos do Complexo ultramáfico-alcalino de Catalão I, GO. In: SBG, Congr. Bras. Geol., 28, Anais, Porto Alegre, v. 5:107-123.

Chakhmouradian A.R. \& Mitchell R.H. 1998. Lueshite, pyrochlore and monazite-(Ce) from apatite-dolomite carbonatite, Lesnaya Varaka complex, Kola Peninsula, Russia. Min. Mag. 62:769-782.

Deer W.A., Howie R.A., Zussman J. 1962. Rock-forming minerals, vol. 5: Non silicates. John Wiley and sons, Inc., N. York, 371pp.

Del Blanco M., Costas Ulbrich M., Echeveste H., Vlach S.R.F. 1998. Las monacitas-(Nd) con samario de los diques carbonatiticos del sector nororiental de la Sierra de Cobres, Salta, Argentina. In: IV Reunion de Miner. y Metalogenia, Univ. Nac del Sur, Bahia Blanca, Argentina, p.63-69.

Ewing R.C. \& Wang L. 2002. Phosphate as nuclear waste forms. In: Kohn, Rakovan \& Hughes, (eds.) Phosphates Geochemical, Geobiological, and materials importance. Reviews in Mineralogy and Geochemistry, 48:673-699.

Farmer V.C. 1974. The Infrared Spectra of Minerals. Mineralogical Society, London, 539pp.

Fleischer M., Rosenblum S., Woodruff M. 1990. The distribution of lanthanides and ytrium in the minerals of the monazite family. U.S. Geol. Survey. Open-File Repport 91-580, 125pp.

Hecht L. \& Cuney M. 2000. Hydrothermal alteration of monazite in the Precambrian crystalline basement of the Athabasca Basin (Saskatchewan, Canada): Implications for the formation of unconformity-related uranium deposits. Mineralium Deposita, 35:791-795.

Hezel A. \& Ross S.D. 1966. Forbbiden transitions in the IR spectra of tetrahedral anions. III. Spectra-structure correlations in perchlorates, sulphates and phosphates of the formula $\mathrm{MXO}_{4}$. Spectrochimica Acta, 22:1949-1961. 
Hughes J. M., Cameron M., Crowley K. D. 1989. Structural variations in natural F, $\mathrm{OH}$, and $\mathrm{Cl}$ apatites. Am. Mineral., 74, 870-876,

Huminicki D.M.C. \& Hawthorne F.C. 2002. The crystal chemistry of the phosphate minerals. In: Kohn, Rakovan \& Hughes (eds.) Phosphates: Geochemical, Geobiological, and materials importance. Reviews in Mineralogy and Geochemistry, 48: 123-253.

Jarosewich E. \& Boatner L.A. 1991. Rare-earth element reference samples for electron microprobe analysis. Geostand. Newsl., 15(2):397-399.

Kucha H. 1980. Continuity in the monazite-huttonite series. Min. Mag. 43:1031-1034.

Lapido-Loureiro F.E. de V. 1994. Terras-Raras no Brasil: Depósitos, Recursos Identificados, Reservas. Rio de Janeiro. MCT, CNPq, CETEM, Série Estudos e Documentos 21, 183p.

Lapido-Loureiro F.E.V. 1995. A mega província carbonatítica BrasilAngola e seus recursos minerais - Geologia, Petrografia, Geoquímica, Geologia Econômica. Tese de Doutoramento, Universidade de Lisboa, Faculdade de Ciências, 305p.

Larson A.C. \& Von Dreele R.B. 1994. General Structure Analysis System (GSAS). Los Alamos National Laboratory Report, LAUR 86-748.

Leonardos Jr. O.H. 1974. Origin and provenance of fossil and recent monazite deposits in Brazil. Econ. Geol., 69:1126-1128.

Levien L., Prewitt C. T., Weidner D. J. 1980. Structure and elastic properties of quartz at pressure $\mathrm{P}=1 \mathrm{~atm}$. Am. Mineral., 65, 920930 .

Lottermoser B.G. 1988. Supergene, secondary monazite from the Mt. Weld carbonatite laterite, Western Australia. N. J. Min. Mon., 2:6770 .

Lottermoser B.G. 1990. Rare-Earth element mineralization within the Mt. Weld carbonatite laterite, Western Australia. Lithos, 24:151-67.

Mariano A.N. 1989. Economic Geology of Rare Earth Minerals. In: Lipin \& McKay (eds.) Geochemistry and Mineralogy of Rare Earth elements, Reviews in Mineralogy 21:309-337.

McCarthy G.J., White W.B., Foertsch D.E. 1978. Synthesis of nuclear waste monazites, ideal actinide hosts for geological disposal. Mat. Res. Bull, 13:1239-1245.

Mitchell R.S., Swanson S.M., Crowley J.K. 1976. Mineralogy of a deep weathered perrierite-bearing pegmatite, Bedford County, Virginia. Southeast. Geol., 18:37-47.

Miyawaki R. \& Nakai I. 1996. Crystal chemical aspects of rare earth minerals. In: A.P. Jones, F. Wall, C.T. Williams (eds.) Rare Earth minerals, The Mineralogical Series. 7, The Mineralogical Society, London, pp. 21-39.

Molloy M.W. 1959. A comparative study of ten monazites. Amer. Min., 44:510-532.

Montel J.M., Lhote F., Claude J.M. 1989. Monazite end members and solid solutions: synthesis, unit-cell characteristics, and utilization as microprobe standards. Min. Mag., 53:120-123.

Morteani G. \& Preinfalk C. 1996. REE distribution and REE carriers in laterites formed on the alkaline complexes of Araxá and Catalão (Brasil). In: A.P. Jones, F. Wall, C.T. Williams (eds.) Rare Earth minerals, The Mineralogical Series. 7, The Mineralogical Society, London, pp. 227-256.

Neumann R. 1999. Caracterização tecnológica dos potenciais minérios de terras-raras de Catalão I, GO. Tese de Doutoramento, Instituto de Geociências, Universidade de São Paulo, 204p.

Ni Y., Hughes J.M., Mariano A.N. 1995. Crystal chemistry of the monazite and xenotime structures. Am. Miner. 80:21-26.

Oliveira S.M.B. de \& Imbernon R.A.L. 1998. Weathering and REE concentration in the Catalão I carbonatitic complex, Central Brazil. J. South Amer: Earth Sci., 11(4):379-388.
Overstreet W.C. 1967. The geological occurrence of monazite. Geol. Surv. Prof. Paper 530, 327p.

Pereira V.P. 1995. Alteração no Maciço Alcálino-carbonatítico de Catalão I (GO, Brasil). Evolução mineralógica. Tese de Doutoramento, Instituto de Geociências, Universidade Federal do Rio Grande do Sul, 279p.

Poitrasson F., Chenery S., Shepperd T.J. 2000. Electron microprobe and LA-ICP-MS study of monazite hydrothermal alteration: implications for U-Th-Pb geochronology and nuclear ceramics. Geochim. Chosmochim. Acta, 64:3283-3297.

Read D., Andreolli M.A.G., Knoper M., Williams C.T., Jarvis N. 2002. The degradation of monazite: Implications for the mobility of rareearth and actinide elements during low-temperature alteration. Eur: $J$. Mineral., 14:487-498.

Ribeiro C.C. 1998. Maciço de Catalão I, GO. Relatório interno, Ultrafértil. $15 \mathrm{p}$.

Rodrigues C.S. \& Lima P.R.A.S.L. 1984. Complexos carbonatíticos do Brasil. In: Companhia Brasileira de Metalurgia e Mineração. CBMM, $17 \mathrm{p}$.

Rose H.J., Blade L.V., Ross M. 1958. Earthy monazite at Magnet Cove, Arkansas. Amer: Miner., 43:995.

Rosenblum S. \& Mosier E.L. 1983. Mineralogy and occurrence of europium-rich dark monazite. USGS Prof. Paper, 1181:1-67.

Steinfink H. \& Sans F. J. 1959. Refinement of the crystal structure of dolomite. Am. Mineral., 44, 679-682.

Tassinari M.M.M.L., Kahn H., Sant 'Agostino L.M., Ratti G., Barros L.A.F. de 1998. Caracterização tecnológica preliminar no saprolito mineralizado a terras raras associado ao domo alcalino de Catalão I, GO. In: XVII Enc. Nac. de Tratamento de Minérios e Metalurgia Extrativa. ABM, 419-430.

Toledo M.C.M. 1999. Mineralogia dos principais fosfatos do maciço alcalino-carbonatítico de Catalão I (GO) e sua evolução no perfil laterítico. Tese de Livre Docência, Instituto de Geociências, Universidade de São Paulo, 198p.

Toledo M. C. M. de, Ferrari V.C., Alcover Neto A., Fontan F., Martin F., Santos C.N., Carvalho F.M.S. 2002. Fosfatos aluminosos com ferro do grupo da crandallita nas coberturas lateríticas de Catalão I, Juquiá e Tapira, Brasil, e Chiriguelo, Paraguai. Rev. Bras. Geoc., 32(4):389402.

Traversa G., Gomes C.B., Brotzu P., Buraglini N., Morbidelli L., Principato M.L., Ronca S., Ruberti E. 2001. Petrography and mineral chemistry of carbonatites and mica-rich rocks from the Araxá Complex. An. Acad. Bras. de Ciências, 73(1):71-98.

Ulbrich H.G.J. \& Gomes C.B.G. 1981. Alkaline rocks from continental Brazil. Earth Sci. Rev, 17:135-154.

Van Wambeke L. 1971. The problem of cation deficiencies in some phosphates due to alteration processes. Am. Mineral., 56:1366-1384.

Valarelli J.V. 1971. O minério de nióbio, titânio e terras raras de Catalão, GO. Tese de Livre-Docência. Instituto de Geociências, Universidade de São Paulo, 104p.

Wall F. \& Mariano A.N. 1996. Rare earth minerals in carbonatites: a discussion centred on the Kangankunde Carbonatite, Malawi. In: A.P. Jones, F. Wall, C.T. Williams (eds.) Rare Earth minerals, The Mineralogical Series. 7, The Mineralogical Society, London, pp. 193226.

Manuscrito A-1428

Recebido em 20 de abriul de 2003

Revisão dos autores em 15 de janeiro de 2004 Revisão aceita em 05 de fevereiro de 2004 